\title{
Experimental study on reinforced concrete walls with opening strengthened by externally bonded CFRP
}

\author{
Mehdi M Lima1, Jeung-Hwan Doh ${ }^{2 *}$, Muhammad N.S. Hadi ${ }^{3}$ \\ ${ }^{1}$ Griffith University, School of Engineering, Gold Coast Campus, QLD 4222, Australia \\ ${ }^{2}$ Griffith University, School of Engineering, Gold Coast Campus, QLD 4222, Australia \\ ${ }^{3}$ School of Civil, Mining and Environmental Engineering, University of Wollongong, NSW 2522, Australia \\ "Correspondence to: Jeung-Hwan Doh, Griffith University, School of Engineering, Gold Coast Campus, QLD 4222, \\ Australia; E-mail: J.doh@griffith.edu.au
}

\section{Abstract:}

Reinforced Concrete (RC) walls with opening under eccentric axial loads exhibit cracks around the opening leading to reduction in the ultimate strength of wall. These cracks are mainly due to changes in load path within the wall and stress concentration around the opening.

Strengthening is usually required to enhance the ultimate strength of the wall and Carbon Fibre Reinforced Polymer (CFRP) is a suitable option for this purpose. In this paper, eighteen (18) one-third scaled RC walls with opening were strengthened using seven distinct Externally Bonded (EB) CFRP layouts and were loaded up to failure under various support conditions. These walls, were subjected to a uniformly distributed axial load with an eccentricity of one sixth of the wall's thickness. Crack patterns, failure modes, ultimate strength, and typical strain measurement of CFRP-concrete interface are presented and discussed in detail. The experimental outcomes revealed that CFRP layout enhance the ultimate strength of RC walls between $14.0-59.7 \%$ and $3.0-40.8 \%$ for walls under one-way and two-way actions, respectively. The efficiency of each CFRP layout is also investigated to prioritise the appropriate layouts for each specific support condition.

Keywords: CFRP; RC wall; de-bonding; strengthening; supports. 
Reinforced Concrete (RC) structures require strengthening/retrofitting due to deterioration caused by environmental effects, poor initial construction, excessive loading, or a lack of required maintenance. RC walls often experience eccentric loading conditions due to imperfections in construction, corbel elements attached to the wall, uneven loading conditions on top of the wall, or temporary loading during/after construction. Presence of an opening within $\mathrm{RC}$ wall under eccentric axial load results in cracks around the opening and a reduction in load carrying capacity.

Load bearing walls with free vertical edges that are only restrained on top and bottom behave in one-way action (see Fig. 1 (a)). In core of tall buildings, axially loaded walls behave in twoway action when restrained on three sides (Fig. 1 (b)) or four sides (see Fig. 1 (c)). A typical crack pattern and curvature scenario for a wall with single opening behaving in one-way action and two-way action is also depicted in Fig. 1. By providing side supports, the wall exhibits double curvature behaviour in both parallel and perpendicular directions shown as X-axis and Y-axis in Fig. 1 (a).

Carbon Fibre Reinforced Polymer (CFRP) is a suitable option for strengthening RC walls by enhancing the ultimate strength. National codes and standards devote separate chapters for FRP applications in RC members (ACI 440- 2008; FIB-14 2001; JSCE 2000; TR 55 2012). The behaviour of RC walls without FRP strengthening scheme has been investigated considering various material properties, geometry, and support conditions ( Ho and Doh, 2018; Ho et al. 2017; Popsecu et al. 2015, 2016; Sabau et al. 2016; Doh and Fragomeni 2005; Doh and Fragomeni 2006; Fragomeni et al. 2012; Saheb and Desayi 1989, 1990) and guidelines have been provided to design the RC walls (ACI-318 2014; AS3600 2009). However, limited 
Mohammed et al. (2013) proposed design equations based on experiments of eight RC walls under one-way action with two different CFRP layouts. Various opening (window) sizes (5, 10, 20, 30 percentage) were considered at the centre of the RC wall. The specimens had an aspect ratio $\left(H_{w} / L_{w}\right)$, slenderness ratio $\left(H_{w} / t_{w}\right)$ and thinness ratio $\left(L_{w} / L_{w}\right)$ of 2,20 , and 10, respectively. The test outcomes indicated that the Externally Bonded (EB) CFRP applications on RC walls in one-way action would increase the ultimate strength of walls between $8 \%$ and $90 \%$, depending on the opening size and CFRP layout. Mohammed et al. (2013) reported that applied CFRP layout with 45 degree angle to the opening corners resulted in a higher contribution to ultimate strength in comparison to cases where CFRP were applied all around the opening.

Lima et al. (2016) completed a FE analysis on CFRP strengthened RC walls with opening in one-way action with two different CFRP patterns. It was evident that the CFRP has greater contribution in ultimate strength of the wall when the opening size increases and more CFRP is applied. The investigation also revealed that for wall with one-way action, the application of CFRP layout with $45^{0}$ to the opening corners resulted in a lower enhancement in ultimate strength in comparison to the case of wall with CFRP applied all around (0/90 degree) the opening. This finding was in contradict with the outcome presented by Mohammed et al. (2013). Unlike the experiment's outcome presented by Mohammed et al. (2013), the FEM simulation showed that the wall with CFRP applied all around (0/90 degree) the opening had a better effect on the strength of the RC wall, as the weakest part of the wall was strengthened.

Popescu et al. (2016) conducted an experimental investigation on FRP strengthened RC walls with door-opening with four sides restraints (TW4S). The FRP was wrapped around the opening with a mechanical anchorage system. Some specimens were pre-cracked by loading up to $75 \%$ of the wall axial capacity and some other were un-cracked. FRP-confinement and mechanical anchorages increased the axial capacity of walls with small (25\%) and large (50\%) 
openings by $34-50 \%$ and $13-27 \%$, respectively. This enhancement in ultimate load is equivalent up to $94.8 \%$ and $63.4 \%$ of the corresponding solid wall, respectively. Concrete crushing of wall and de-bonding of FRP sheet was observed at ultimate load.

Popescu et al. (2017) proposed a formula to calculate the ultimate load of fully wrapped CFRP walls under axial (in-plane) loading. The contribution of CFRP was calculated indirectly, by updating the concrete model with an enhanced compressive strength as a result of confining the piers (the sides of opening).

A summary of previous experiments outcome is presented in Table 1 in form of dimensionless quantity, i.e. the axial strength ratio and the numbers in the parentheses represents the enhancement (in percentage) of the axial strength ratios between the control walls (without CFRP) and CFRP-strengthened walls for each specimen. For more detailed description about the experiments and findings, the original articles can be referred.

Even though, a few studies have been conducted on CFRP strengthened RC walls, these investigations have some shortcoming that are outlined herein:

a) Previous design formulae for CFRP strengthened walls in one-way action are not applicable for various CFRP layouts. Also, the current formula for CFRP strengthened $\mathrm{RC}$ walls in two-way action is only applicable for specimens with fully wrapped CFRP.

b) Unlike the experiment's outcome (Mohammed et al. 2013), the study conducted by Lima et al. (2016) confirmed that the specimen of CFRP layout with 45 degree angle to the opening corners resulted in a lower contribution to the ultimate strength in comparison to that with CFRP applied all around the opening for walls under one-way action. The current research is aimed to clarify the previous findings.

Hence, additional studies were required to obtain a better understanding of the RC walls' behaviour strengthened with various CFRP layouts and tested under different support 
conditions. Since only the axial load capacities of CFRP strengthened concrete walls with opening was of interest in this study, neither horizontal in-plane nor lateral forces were applied during the experiment. The walls were subjected to a uniformly distributed in-plane axial load with an eccentricity of $t_{w} / 6$ which is the limit scope of the AS3600 (2009).

\section{Test walls and test set up}

\section{Test walls}

Experiments were undertaken on RC walls with and without CFRP layouts, under one-way action ((OW, Fig. 1 (a)) and, two-way action with three sides restrained (TW3S, Fig. 1(b)) and two-way action with four (all) sides restrained (TW4S, Fig. 1(c)). In total, eighteen (18) RC walls were tested up to failure load. The walls are designated as: 1) $\mathbf{O W}$ : one-way buckling with supported top and bottom only; 2) TW3S: two-way buckling with three-side supports; 3) TW4S: two-way buckling with four-side supports. The nomenclature for seven distinguished CFRP were designated as: NF- no CFRP (Control wall); AF- alongside the opening; DFdiagonal to the opening; CF- a combination of AF and DF; WF- a combination of DF and wrapped around the opening's corners; PF- parallel to the opening; MF- a mix of diagonal and parallel layouts to the opening, and FWF-: fully wrapped around the opening. NF, AF, DF, CF, and WF layouts were tested for walls with OW, TW3S, and TW4S. PF and MF layouts were tested for walls with OW and TW3S, respectively. The walls dimensions and CFRP layouts are detailed in Fig. 2.

The dimension of RC walls was $1200 \mathrm{~mm} \times 1200 \mathrm{~mm} \times 40 \mathrm{~mm}\left(H_{w} \times L_{w} \times t_{w}\right)$. For all wall series, slenderness ratio $\left(H_{w} / t_{w}\right)$ was 30 and all walls were axially loaded at an eccentricity of $t_{w} / 6$. In the current AS3600 (2009), the effects of openings can be neglected for TW4S if the total area of the openings is less than $10 \%$ of the area of the wall and the height of any opening is less than $1 / 3$ of the height of the wall. Therefore, in this study the opening ratio of 
123 the wall was selected as 14\% which is beyond the limit of AS3600 (2009) for walls with TW4S

124 to be considered as wall with opening. The size of the opening was constant within all RC walls

125 in order to investigate the efficiency of CFRP layouts between various support condition.

126 CFRP layouts were selected and applied considering the expected behaviour of the wall and 127 observed crack patterns in previous investigations (Fig. 1). Horizontal crack pattern was 128 reported within OW walls, therefore the CFRP was applied perpendicular to the crack direction 129 (AF and CF layouts). However, a CFRP layout was applied 45 degree to the opening to 130 investigate the discrepancy between the outcomes of finite element analysis (Lima et al, 2016) 131 and experimental analysis (Mohammad et al. 213). The effect of the extended CFRP layout 132 was the main focus in wall OW-PF. The wall with MF layout was strengthened by applying 133 CFRP with $45^{\circ}$ near the side support and alongside opening at the free-edge in which the 134 layouts were applied perpendicular to the crack direction. In CF layout, a combination of CFRP 135 layouts in $45^{\circ}$ and alongside opening was applied. The effect of fully wrapped CFRP around 136 the opening is investigated in wall TW3S-FWF where the wall behaves as a slender-column at 137 the free-edge.

138 Strain gauges were installed at critical positions to investigate the potential de-bonding 139 between concrete and CFRP layout in all RC walls. As the primary purpose of this investigation 140 was to analyse the influence of strengthening patterns and the structural behaviour of walls under one-way, and two-way actions, the reinforcement ratios were kept constant for all walls.

142 Single F41 mesh (4 mm diameter, $100 \mathrm{~mm}$ spacing and nominal tensile strength, $\left(f_{y}=500\right.$

$143 \mathrm{MPa}$ ) was placed centrally in the cross section of the walls. This reinforcement ratio was taken 144 approximately the minimum level required by the AS3600 (2009)

145 The concrete was provided by a local ready mix supplier using general purpose cement, 146 sand, and $10 \mathrm{~mm}$ aggregates. No admixtures were used in concrete mixes. The initial concrete 
147 compressive strength for design was equal to $50 \mathrm{MPa}$. Walls were cast horizontally in specially

148 made timber moulds with reinforcement secured at the centre of the cross-section using tie

149 wires on $20 \mathrm{~mm}$ high chairs. High density polystyrene foam was placed in specific positions

150 on the timber moulds to ensure openings were formed in the places required. Walls were cast

151 in batches of six, to maximise the usage of moulds and concrete delivered.

\section{CFRP amount and size}

A simplified method proposed by Enochsson et al. (2007) was utilised to determine the

154 amount of required CFRP for strengthening of RC walls. The concept of their method is to

155 replace the cut reinforcement within the opening with equivalent CFRP sheet around the opening. This method is based on the Swedish Building Administration's handbook on concrete structures BBK04 (2004). Fig. 2 illustrates the CFRP layout for all walls. The width and anchorage length of CFRP layout was calculated based on the following formulae (Eqs. 1-

159 4):

$$
\begin{gathered}
a=\frac{A_{s 2} f_{s y}}{0.85 f_{c}^{\prime} L_{w}} \\
x=\frac{a}{0.85} \\
A_{f}=\frac{E_{s 2}}{E_{f}}\left(\frac{t_{w}-u-x}{t_{w}-x}\right)^{2} A_{s 2} \\
W_{f}=\frac{A_{f}}{t_{f}}
\end{gathered}
$$

160 where: $f_{c}^{\prime}$ is concrete compressive strength; $L_{w}$ is concrete wall length; $f_{s y}$ is steel yield

161 stress; $t_{w}$ and $t_{f}$ are the thickness of wall and CFRP, respectively; $E_{s}$ and $E_{f}$ are modulus of

162 elasticity of steel and CFRP, respectively; $\mathrm{u}$ is concrete cover of reinforcement; $A_{s 2}$ and $A_{f}$ are

163 the area of additional steel reinforcement and CFRP cross sectional area, respectively; $a$ is the

164 depth of the equivalent rectangular stress block, and $W_{f}$ is the width of the required CFRP. 

where a width of $450 \mathrm{~mm}$ was used to fully wrap the opening. In order to have an estimation of the effective anchorage length ( $L_{b \max }$ ) of CFRP, a proposed formula (Eq. 5) for concrete beams was used (CEB-FIP 1993). Based on the recommendation provided in FIB Bulletin 14

169 (2001), an increase in anchorage length does not result in an increase in resisting the tensile stress due to the limitation of fracture energy.

$$
L_{b \max }=c \sqrt{\frac{E_{f^{t} f}}{\sqrt{f_{c t m} f_{c}^{\prime}}}}
$$

171 Where, $c=1.44$ (constant) and $f_{c t m}$ is the tensile strength of the concrete. The effective 172 anchorage length was added to the opening size to calculate the total length of required CFR. 173 An additional length was also added to the CFRP layer to provide a cross coverage of two perpendicular layers. The CFRP material properties are listed for reference in Table 2. The minimum amount of required CFRP sheet is presented in Table 3. For all CFRP applications,

176 the width of layout was the same, while the width of the FWF layout was equal to the opening 177 length.

\section{Application of CFRP layouts}

An epoxy system consisting of two parts, resin and hardener in a weight ratio of 4:1 was used in a dry-layup process. Initially, the well mixed Sikadur-330 [Sika 2014] was applied to the prepared substrate by lamb skin roller. Later, Sika Wrap-230C [Sika2014] was placed onto the resin coating. Finally, the fabric was carefully worked into the resin with a plastic roller until the resin was squeezed out between the rovings. The walls were then left to dry for 14 days as was specified by the supplier. The CFRP layouts were applied on the tension side of the RC walls, except for FWF and WF patterns in which CFRP layer was totally wrapped around the opening or a u-shaped pattern was applied around the corner of opening. 


\section{Test set-up}

The test set-up arrangement is presented in Fig. 3. The test frame was designed to support three independent hydraulic jacks able to apply loads up to $800 \mathrm{kN}$ individually. The hydraulic jacks applied a uniformly distributed load across the top of the wall at an eccentricity of $t_{w} / 6$ . The 250UC72 supporting beam on the strong floor was identical to the loading beam at top.

The top and bottom hinged support conditions were each simulated by placing a $40 \mathrm{~mm}$ mm equal angles were clamped to the thick plate using bolts. The steel rod was welded along the steel plate at an eccentricity of $t_{w} / 6$. Details of the simply supported top hinged edge are presented in Fig. 3(b). To achieve the hinged side support conditions for two-way action, the edges of the walls had to be effectively stiffened in the perpendicular direction to prevent rotation around the $\mathrm{X}$-axis while allowing rotation around the $\mathrm{Y}$-axis ( $\mathrm{X}$ and $\mathrm{Y}$ axes are shown in Fig. 1). To achieve this, two 150 Parallel Flange Channels (PFC) separated by a Square Hollow Section (SHS) extending along the height of both sides of the test wall were used (Fig. 3(c)). The side restraints were tied up with high tensile bolts (with $16 \mathrm{~mm}$ diameter at $100 \mathrm{~mm}$ span) through the SHS, to take advantage of the stronger axis of the section. Dial gauges were used to measure the deflections of the walls during testing (Fig. 3(a)). The position of dial gauges on the walls during the experiments is presented in Fig. 4. Four dial gauges were positioned midway between the edges of the panel and the edges of the opening to measure out-of-plane deflections. A single dial gauge was also installed to measure the vertical shortening or in-plane deflection of the $\mathrm{RC}$ wall. Strain gauges were also installed to monitor the critical points such as the corner of the wall openings, top of the CFRP and at the CFRPconcrete interface for detecting any potential de-bonding. In Fig. 2, the location and type of strain gauges for each test sample is presented. The Rossete strain gauges were installed on the

211 corner of the opening (Fig, 2(a)). For clarity, the Rossete strain gauges are not shown on the

212 CFRP strengthened walls. The orange and blue colours are representing the concrete and CFRP 
strain gauges, respectively.

\section{Test procedure}

A static loading regime was adopted for the experiment. A load cell was positioned at the centre of the hydraulic jacks on top of the loading beam. Load was applied per hydraulic jack incrementally at $4.9 \mathrm{kN}$ up to failure (force controlled). Due to lack of equipment and facility for completion of test using displacement control, the force control approach was utilised.

\section{Experimental results and discussion}

\section{Crack Patterns}

\section{One-way action (OW)}

Provided restraints at top and bottom, the RC walls experience horizontal cracks throughout the middle of the opening, as shown in Fig. 5 (a). For the OW-NF wall without CFRP, similar bending failure for RC walls with opening under eccentric axial loading has been reported in the previous studies (Doh and Fragomeni 2006; Fragomeni et al. 2012).

The crack patterns after failure, observed on the tension face of the walls tested under oneway action, are presented in Figs. 5(b), 5(c), 5(d), 5(e), and 5(f). In most cases, more distributed cracks were observed for strengthened walls compare to corresponding control sample.

Wall OW-DF presented a few large cracks on the tension face, similar to the failure mode observed for the wall OW-NF. This indicates that the DF layout in walls under one-way action did not provide sufficient contribution to the performance of the wall accompanying a brittle failure. In contrast to the findings in Mohammed et al. (2013) which reported above 50\% increase in ultimate load for a similar size of opening, the results revealed only a $15 \%$ increase in the ultimate strengths between OW-DF and OW-NF walls. The CFRP application alongside the opening for OW-AF, OW-CF, and OW-PF walls resulted in more distributed cracks within the RC walls around the opening on the tension side in compare to OW-DF and OW-NF. This observation indicates that these CFRP layouts enhanced the performance and ultimate strength 
of the walls. Although bending failure was predominant in these walls, there was adequate evidence to confirm that some compressive crushing failure also occurred.

For OW-WF wall, a catastrophic collapse was observed with some reinforcements yield.

The failure pattern for this wall was still a flexural bending failure. The brittle nature and failure across the thickness of the wall is due to load transferring between compression and tension faces of the walls as the u-shaped CFRP was wrapped around the corner of the opening.

As shown in Figs. 5(b), 5(c), 5(d), 5(e), and 5(f), on the tension side of the walls, there was no evidence of de-bonding between CFRP and concrete before ultimate load was reached. For walls OW-DF and OW-WF, there was no evidence of de-bonding even after failure load (Figs. 5(b) and 5(e)). Further details are presented in strain gauge data measurement section.

\section{Two-way action with three sides restrained (TW3S)}

The tested TW3S walls exhibited crack patterns and failure modes that were consistent with the expected behaviour of walls supported on three sides. Biaxial curvature was evident as idealised in Fig. 1(b). It is evident that the majority of cracking propagated diagonally from the restrained corners to the opening and then horizontally from the opening to the unrestrained edge. This unique cracking mode indicates a typical two-way behaviour close to the restrained ends and one-way behaviour close to free edge. Similar crack patterns were reported in the experimental tests conducted by Doh et al. (2010) as highlighted in Fig. 6 (a), crack patterns due to the resistance provided by CFRP (Figs. 6(b), 6(c), 6(d), 6(e), 6(f), and 6(g)). Walls with CFRP perpendicular to the crack direction (TW3S-DF, -CF, -WF and -MF) represents more ductile behaviour with more distributed. In TW3S-AF wall, three large cracks were observed within the wall propagating from the restrained corners on tension side towards 
262 free edge. This observation indicates a brittle failure mode with possible yielding of some

263 reinforcement. In contrast, TW3S-FWF wall presented more ductile behaviour with a few

264 parallel cracks. As no CFRP layer was used perpendicular to the crack direction near the

265 restrained corners, the crack pattern was analogous to that observed on walls without CFRP.

266 In this case, the fibre orientation was parallel to the crack propagation in the free edge.

\section{Two-way action with all four sides restrained (TW4S)}

The crack patterns on the tension face of wall TW4S walls are presented in Fig 7. The TW4S-NF wall showed typical double curvature bending failure characterised by diagonal cracking from the wall's corners propagating towards the corner of the opening, similar to the ideal scenario as shown in Fig. 1(c).

A distinct difference was also observed in failure modes of TW4S walls strengthened with

273 CFRP layouts where more smeared diagonal cracks were evident within the tension side of the wall propagating from the restraints towards the corner of the opening (Figs. 7 (b) and 7(e)). irregularities and loading condition; however, the anticipated crack pattern was generally observed in most cases. In these cases, the CFRP was also bonded with the substrate until the failure load was achieved.

\section{Deflection measurement}

The loads versus out-of-plane and in-plane deflections for all walls are presented in Figs. 8 to 10 . The vertical in-plane deflections were also recorded to investigate shortening of the walls. The maximum deflections were obtained just prior to the failure load being reached. The failure behaviour in most of the walls was brittle mode and the deflection at the last stage of loading was not recorded due to sudden failure. Thus, in these figures, the absolute maximum failure loads and the corresponding maximum deflections are not shown. 
midway between the free edge of the wall and the edges of the opening (shown as Right Gauge in Fig. 4). As shown in Figs. 8, 9, and 10, the maximum shortenings (in-plane vertical deflection) were generally smaller than the maximum out-of-plane deflection in most of the $\mathrm{RC}$ walls. Smaller vertical shortenings (in-plane deflection) were recorded in RC walls under one-way action in comparison to TW3S and TW4S walls at the same load level (Figs. 8, 9, and 10).

For OW walls, the recorded out-of-plane deflection at the left side of the opening was similar to that at the right side. The out-of-plane deflection at the top of the opening was slightly greater than that on the bottom of the RC walls. This observation is due to the proximity of the portion of wall to the loading cell at top of the opening. The maximum out-of-plane deflection of strengthened RC walls was increased by various amounts for alternative CFRP layouts. The out-of-plane deflection profile of OW walls showed a fairly uniform curvature along the height with the maximum deflection at the mid-height. Generally, the profile of all the tested walls under one-way action showed similar behaviour in which, in early stages of loading, slight outof-plane deflections were produced and then more pronounced deflections observed as the test walls were progressively loaded to failure.

The distinct advantages of TW3S walls compared to OW walls are also evident with less out-of-plane deflections being achieved for the same load level. The deflections near unrestrained support (Right Gauge) indicate that a greater deflection occurred for all cases in wall TW3S in comparison to that with OW. The vertical shortening (in-plane deflection) of walls TW3S was recorded where greater deflections were observed compared to TW4S walls at the same load level. The out-of-plane deflection profiles for the free edge of walls TW3S were similar to that of walls with OW. Based on out-of-plane deflection profiles, it is obvious that the CFRP layer assisted the walls to sustain greater deflections compared to walls without

311 CFRP. A similar behaviour was observed for some of the walls with four sides restrained 312 (TW4S). 
Generally, in TW4S walls the out-of-plane deflections at the left and right gauges were

314 similar to observed deflections at the top and bottom gauges. This was obvious as the side, top,

315 and bottom-quarter points should have moved, approximately, by the same amount due to the curvatures taking place in both the vertical and horizontal directions. However, an irregular vertical (in-plane) deflection was observed for the wall TW4S-CF (Fig. 10(d)), where the CFRP layout provided a robust lateral support around the opening and the major failure mechanism was concrete crushing at the top restraint. For this case, given the restraint conditions, the CFRP layout was covered large portion of wall and prevented the wall to rotate appropriately. This condition was resulted in excessive stress concentration within the top edge of the wall and localised crushing near support.

\section{Strain gauge data measurements}

Strains were also measured to monitor the critical points such as the corner of the wall openings, top of the CFRP and at the CFRP-concrete interface for detecting any potential debonding. Strains were recorded at each load increment for all RC walls. The tested wall had a brittle mode and the sudden failure of these walls made it difficult to record strain precisely, at the last step of loading. Based on the obtained data and observation, the CFRP was bonded with the substrate until the failure load was achieved. Generally, an abrupt change was noticed in the obtained strain data during the last stage of loading. A few of these outcomes are selected and presented in this section. Fig. 11 presents the location of the strain gauges on top of the CFRP layer and concrete (interface) for OW-CF and Fig. 12 depicts the load versus strain diagram. The measurement of strain on top of the CFRP layout was identical to that of the gauge located at the CFRP-concrete interface. This was further evidence that the concrete and CFRP were intact and fully bonded until the ultimate load was achieved. The loads versus strain were linear for initial loading stages, and then a non-linear trend was observed where strain rapidly increased approaching failure phase. For OW-CF wall, the load-strain curve 
exhibits a linear behaviour up to a loading stage at approximately $30 \%$ of the ultimate load. A

339 similar observation was made for TW3S-CF (Figs. 13 and 14) and TW4S-CF (Figs. 15 and

340 16). For TW3S-CF and TW4S-CF walls, the load-strain curves were essentially linear up to $70-80 \%$ of the ultimate load where a low strain and brittle behaviour was recorded for these walls.

The strain gauges that were installed on top of the CFRP layer did not reveal any abrupt changes in the obtained strain data during testing and before the last stage of loading and failure. Figs. 17, 18, 19 and 20 present the location of the strain gauges and load versus strain curves for walls under OW, TW3S and TW4S strengthened with CF and WF layouts. As shown in Figs. 18 and 20, it is noticeable that the CFRP layer enhanced the ultimate strength of walls and it also remained bonded to the concrete.

\section{Ultimate strength}

The ultimate strength of the walls were recorded and are presented as a dimensionless quantity, i.e. the axial strength $\left(N_{u o} / f^{\prime}{ }_{c} \cdot L_{w} \cdot t_{w}\right)$, shown in Table 4 . In this section, the effect of support conditions and the contribution of CFRP layout in enhancement of the ultimate strength of RC walls are discussed.

In Table 3, the numbers in the parentheses represents the enhancement (in percentage) of the axial strength ratios between the control walls (without CFRP i.e. NF) and CFRPstrengthened walls for each support condition. A comparison between the ratio of ultimate loading of walls under various support condition $\left(N_{u o}(\mathrm{OW}) / N_{u o}(\mathrm{TW} 3 \mathrm{~S})\right.$ and $\left.N_{u o}(\mathrm{OW}) / N_{u o}(\mathrm{TW} 4 \mathrm{~S})\right)$ are also presented in Table 4.

The ultimate strength of RC walls in one-way action was approximately $60 \%$ and $40 \%$ of that of TW3S and TW4S walls, respectively. The results are similar to the experimental tests obtained by Doh et al. (2010) which indicates that adding side supports increases the load capacity of walls irrespective of any type of CFRP layout. 
Alternate CFRP applications resulted in various enhancements in ultimate strength (Table 4). The ultimate strengths of walls under one-way action (OW) with DF, AF, WF, CF and PF layouts resulted in an enhancement of the ultimate strength up to $15.5 \%, 26.2 \%, 25.4 \%, 59.7 \%$, and $14.0 \%$, respectively. However, this observation contradicts the results obtained by Mohammad et al. (2013); they claimed that greater enhancement of ultimate strength is achievable by applying DF pattern rather than AF for OW walls. Although, based on the finding of the current experiment, the higher contribution of CFRP in ultimate strength of OW-AF wall is due to the CFRP application around the weakest part of the wall and it is consistent with the outcomes obtained in a finite element analysis conducted by Lima et al. (2016). $33.2 \%, 40.8 \%, 32.9 \%$, and $3.0 \%$ for DF, AF, WF, CF, MF, and FWF, respectively. The maximum enhancement was observed in RC walls strengthened with $\mathrm{AF}$ and $\mathrm{CF}$ pattern. This is mainly due to the CFRP application around the opening and close to free-edge where the wall has similar behaviour to OW walls. The least contribution in ultimate strength was recorded in RC walls strengthened with FWF layout; this insignificant contribution is mainly due to the fibre orientation which was parallel to crack propagation at the free-edge of the wall. The increases in ultimate strengths were up to $18.4 \%, 19.3 \%, 23.0 \%$, and $24.9 \%$ for $\mathrm{DF}, \mathrm{AF}$, $\mathrm{WF}$, and CF layouts, respectively. The maximum contribution in ultimate strength was observed for RC walls strengthened with WF and CF layouts. This observation was mainly due to the application of CFRP perpendicular to the crack direction.

The study revealed that the axial strength ratio of the walls with $\mathrm{CF}$ layout is the largest value that represents the maximum enhancement in ultimate strength of $\mathrm{RC}$ walls. This indicates that $\mathrm{CF}$ layout may be the best strengthening or retrofitting pattern for walls under any support conditions. 
corresponding gain in ultimate strength. For more clarification, the efficiency of each CFRP

390 layout was considered as the ratio of ultimate strength enhancement (\%) to the total length of

391 CFRP layout $\left(L_{C F R P}\right)$.

392 The findings indicated that the WF pattern resulted in the least efficient layout and minimum

393 enhancement in ultimate strength considering the amount of used CFRP in all three categories

394 of walls under OW, TW3S, and TW4S.

395 For OW walls, the greatest efficiency was obtained for RC walls strengthened with CF

396 layout where ultimate strength was significantly enhanced up to 59.7\%. The AF and DF layouts

397 resulted in similar efficiency while the lowest efficiency was observed for the walls with PF 398 and WF layouts.

399 For TW3S walls, the maximum efficiency was obtained in walls with DF layout in which

400 the minimum amount of CFRP was utilised. Also, the maximum usage of CFRP was for the

401 FWF pattern, the lowest efficiency was reached in this case. Noteworthy, both DF and WF

402 layouts resulted in identical enhancements in ultimate strength, while the amount of applied

403 CFRP for the WF pattern was triple than that for DF layout. The AF and CF pattern improved 404 the capacity of RC walls identically (by 40.8\%); however, the efficiency of DF pattern is clearly 405 superior to that of AF.

406 Generally, an identical enhancement in ultimate strength was observed for TW4S walls;

407 however, the DF layout resulted in the optimum efficiency in enhancement of ultimate strength.

\section{Conclusions}

409 Fifteen CFRP strengthened and three reference RC walls with opening were constructed and

410 tested under eccentric axial loads. Seven types of CFRP layouts were considered and the effect

411 of these layouts on the behaviour of $\mathrm{RC}$ walls was examined under three distinct support

412 conditions. The conclusion of this research is outlined herein: 
- Various level of enhancement in ultimate strength of RC walls was achieved under different support conditions and CFRP layouts. For OW walls, an enhancement of ultimate strength between $14.0-59.7 \%$ was observed, while this range for walls under TW3S and TW4S was between 3.0-40.8\% and 18.4-24.9\%, respectively.

- The ultimate strength of OW walls was approximately $60 \%$ and $40 \%$ of that with TW3S and TW4S, respectively.

- CFRP application changed the load path around the opening and provide more rigidity to the walls around the opening and ease the load transferring to the bottom restraint. This condition altered the crack patterns due to the resistance of the CFRP provided. This was more obvious in cases where the CFRP was applied perpendicular to the typical cracks direction resulted in more distributed cracks.

- Generally, more deflection was observed in CFRP strengthened RC walls compared to that without CFRP. However, due to brittle failure of the walls, the deflection at last step was not recorded.

- De-bonding was not an issue before failure load. This conclusion is based on the obtained data and observations during the test. This finding indicates that additional amount of EB-CFRP for anchoring purposes might not be essential for strengthening RC walls.

- The efficiency investigation of CFRP layouts was also completed. FWF layout was the least efficient pattern of strengthening while it was totally wrapped around the wall. The CF and DF were the most effective layouts for walls under one-way and two-way action, respectively. Application of CFRP perpendicular to the crack direction significantly enhanced the ultimate strength of the wall in compare to the case where the CFRP was not applied perpendicular to the crack direction. 
Further research is required to determine the behaviour of $\mathrm{RC}$ walls with various opening sizes and locations using alternative CFRP layouts. The outcomes of this study provide a platform to establish a future reliable FEM model to conduct parametric studies considering the effects of various factors.

\section{Acknowledgments}

The authors wish to acknowledge an in-kind contribution from SIKA Australia Pty. Ltd by providing the CFRP material and epoxy. The authors also express their thanks to the concrete lab technicians at Griffith University, School of Engineering. The authors wish to acknowledge an in-kind contribution from Dr Mojtaba Ale-Mohamamdi for proofreading of this paper.

\section{References}

ACI (American Concrete Institute). (2014). “Building code requirements for structural concrete and commentary." ACI 318, Farmington Hills, MI.

ACI (American Concrete Institute). (2008). “ Guide for the design and construction of externally bonded FRP systems for strengthening concrete structures. " ACI 440, Farmington Hills, MI.

AS (Australian Standard). (2009). “Concrete Structures”. AS3600, Standards Association of Australia, 176.

BBK04,(Boverkets Handbok om Betongkonstruktioner.). (2004). Sweden. "The Swedish Building Administration's Handbook on Concrete Structures": The Swedish Building Administration, Division of Buildings.

CEB-FIP Model Code 90 (1993), Comité Euro-International du Beton, Bulletin d'Information no. 213/214, Ed. Thomas Telford.

Doh, J.-H., and Fragomeni, S. (2005). "Evaluation of experimental work on concrete walls in one and two-way action." Aust. J. Struct. Eng. 6(1), 37.

Doh, J.-H., and Fragomeni, S. (2006). "Ultimate load formula for reinforced concrete wall panels with openings". Adv. Struct. Eng., 9(1), 103-115. 
462

463

464

465

466

467

468

469

470

471

472

473

474

475

476

477

478

479

480

481

482

483

484

485

486

487

488

Doh, J.-H., Loo, Y., and Fragomeni, S. (2010). “Concrete walls with and without openings supported on three sides." Incorporating sustainable practice in mechanics and structures of materials. Taylor and Francis Group, 209-214.

Enochsson, O., Lundqvist, J., Täljsten, B., Rusinowski, P., and Olofsson, T. (2007). "CFRP strengthened openings in two-way concrete slabs-An experimental and numerical study." Construc. Build. Mater., 21(4), 810-826.

Fib Bullettin 14. (2001). "Externally bonded FRP reinforcement for RC structures." Federation Internationale du Beton.

Fragomeni, S., Doh, J.-H., and Lee, D. (2012). "Behavior of Axially Loaded Concrete Wall Panels with Openings: An Experimental Study.” Adv. Struc. Eng., 15(8), 1345-1358.

Ho, N. M., Doh, J. H., and Fragomeni, S. (2017). Instability analysis of reinforced concrete walls with various support conditions. Struct. Des. Tall Spec, 26(7).

Ho N. M., and Doh J-H. "Experimental and numerical investigations of axially loaded RC walls restrained on three sides." Struct. Des. Tall Spec. 2018; e1459. https://doi.org/10.1002/tal.1459

JSCE (Japanese Society of Civil Engineers). (2000), "Recommendations for upgrading of concrete structures with use of continuous fiber sheets." Research Committee on Upgrading of Concrete Structures with Use of Continuous Fiber Sheets,

Mohammed, B. S., Ean, L., and Malek, M. (2013)." One way RC wall panels with openings strengthened with CFRP.” Construc. Build. Mat., 40, 575-583.

Lima, M. M., Doh, J.-H., Hadi, M. N. S., and Miller, D. (2016), “The effects of CFRP orientation on the strengthening of reinforced concrete structures." Struct. Des. Tall Spec. doi: $10.1002 /$ tal. 1282

Popescu, C., Sas, G., Blanksvärd, T., and Täljsten, B. (2015). “Concrete walls weakened by openings as compression members: A review." Eng. Struct., 89, 172-190.

Popescu, C., Sas, G., Sabău, C., and Blanksvärd, T. (2016). "Effect of cut-out openings on the axial strength of concrete walls." J. Struct. Eng, 142(11), 04016100. 
Popescu, C., Sas, G., Blanksvärd, T., and Täljsten, B. (2016). “Concrete Walls with Cutout Openings Strengthened by FRP Confinement." J. Comp. for Construc., 21(3), 04016106.

Popescu, C., Schmidt, J. W., Goltermann, P., and Sas, G. (2017). “Assessment of RC walls with cut-out openings strengthened by FRP composites using a rigid-plastic approach." Eng. Struc, 150, 585-598.

Sabau, C., Popescu, C., Sas, G., Blanksvärd, T., and Täljsten, B. (2016). "Monitoring structural behavior of reinforced concrete walls with openings using digital image correlation." Paper presented at the 19th IABSE Congress, Stockholm 2016, September 21-23.

Saheb, S. M., and Desayi, P. (1989). "Ultimate strength of RC wall panels in one-way in-plane action." J. Struct. Eng. , 115(10), 2617-2630.

Saheb, S. M., and Desayi, P. (1990). "Ultimate strength of RC wall panels with openings.” J. Struct. Eng., 116(6), 1565-1577.

Sika Australia Pty Ltd. (2014)., "Sika Product Data Sheet, SikaWrap -230 C", Identification no: 0204 01020010000025

TR 55. (2012). “ Design guidance for strengthening concrete structures using fibre composite materials. "Concrete Society, UK.

\begin{tabular}{|c|c|}
\hline & NOTATION \\
\hline$a$ & $=$ the depth of the equivalent rectangular stress block \\
\hline$A_{f}$ & $=\frac{E_{s 2}}{E_{f}}\left(\frac{t_{w}-u-x}{t_{w}-x}\right)^{2} A_{s 2}$, the CFRP cross sectional area \\
\hline$A_{s 2}$ & $=$ the area of additional steel reinforcement \\
\hline$e$ & $=$ the load eccentricity $(\mathrm{mm})$ \\
\hline$E_{f}$ & $=$ the modulus of elasticity of CFRP in principal direction \\
\hline$E_{s}$ & $=$ elastic modulus of steel \\
\hline$f_{c t m}$ & $=$ the tensile strength of the concrete \\
\hline$f_{c}^{\prime}$ & $=$ the yield strength of concrete in $\mathrm{MPa}$ \\
\hline$f_{s y}$ & $=$ steel yield stress \\
\hline$f_{y}$ & $=$ the yield strength of steel in $\mathrm{MPa}$ \\
\hline$H_{o}$ & $=$ the dimension of the opening height in $\mathrm{mm}$ \\
\hline HSC & $=$ High Strength Concrete \\
\hline
\end{tabular}




$\begin{array}{ll}H_{w} & =\text { the height of the wall in mm } \\ L_{b \text { max }} & =c \sqrt{\frac{E_{f} t^{\prime}}{\sqrt{f_{c t m} f^{\prime} c}}} \text {, effective anchorage length } \\ & =\text { the length of CFRP layout } \\ & =\text { the dimension of the opening length in mm } \\ \mathrm{L}_{\mathrm{CFRP}} & =\text { the length of the wall in mm } \\ L_{o} & =\text { the ultimate load of CFRP strengthened RC walls using AF layout } \\ L_{w} & =\text { the ultimate load of CFRP strengthened RC walls using CF layout } \\ \mathrm{N}_{\mathrm{AF}} & =\text { the ultimate load of CFRP strengthened RC walls using DF layout } \\ \mathrm{N}_{\mathrm{CF}} & =\text { the ultimate load of CFRP strengthened RC walls using NF layout } \\ \mathrm{N}_{\mathrm{DF}} & =\text { the ultimate design axial strength of wall per unit length (in } \\ \mathrm{N}_{\mathrm{NF}} & \text { N/mm) } \\ \mathrm{N}_{\mathrm{uo}} & =\text { the ultimate load of CFRP strengthened RC walls using WF } \\ \mathrm{N}_{\mathrm{WF}} & =\text { layout } \\ \mathrm{OW} & =\text { CFRP thickness } \\ t_{f} & =\text { the resin thickness } \\ t_{i} & =\text { the wall thickness } \\ t_{w} & =\text { two-way buckling with three sides supported; } \\ \mathrm{TW} 3 \mathrm{~S} & =\text { two-way buckling with four sides supported } \\ \mathrm{TW} 4 \mathrm{~S} & =\text { concrete cover of reinforcement (mm) } \\ u & =A_{f} / t_{f}, \text { width of the required CFRP } \\ W & \end{array}$


Table 1-summary of previous study on CFRP-strengthened RC walls

\begin{tabular}{|c|c|c|c|c|c|c|c|c|c|c|c|c|}
\hline \multirow{2}{*}{ Refs } & \multirow{2}{*}{ Specimen } & \multicolumn{3}{|c|}{$\begin{array}{l}\text { Geometrical Dimension } \\
(\mathrm{mm})\end{array}$} & \multicolumn{2}{|c|}{$\begin{array}{l}\text { Opening Dimension } \\
(\mathrm{mm})\end{array}$} & \multirow{2}{*}{$\begin{array}{l}\text { Type of } \\
\text { Opening }\end{array}$} & \multirow{2}{*}{$\begin{array}{c}\text { Wall } \\
\text { Condition }\end{array}$} & \multirow{2}{*}{$\begin{array}{c}\text { Type of } \\
\text { CFRP } \\
\text { application }\end{array}$} & \multirow{2}{*}{$\begin{array}{c}f_{c}^{{ }^{3}} \\
(\mathrm{MPa})\end{array}$} & \multirow{2}{*}{$\begin{array}{c}\text { Capacity } \\
N_{u o}^{4} \\
(\mathrm{kN})\end{array}$} & \multirow{2}{*}{$\begin{array}{c}\text { Axial strength } \\
\text { ratio } \\
N_{u o} /\left(f_{c}^{\prime} . L_{w} \cdot t_{w}\right)\end{array}$} \\
\hline & & $\begin{array}{c}\text { Height } \\
H_{w}\end{array}$ & $\begin{array}{l}\text { Width } \\
L_{w}\end{array}$ & $\begin{array}{l}\text { Thickness } \\
t_{w}\end{array}$ & $\begin{array}{c}\text { Height } \\
H_{o}\end{array}$ & $\begin{array}{c}\text { Width } \\
L_{o}\end{array}$ & & & & & & \\
\hline \multirow{6}{*}{ 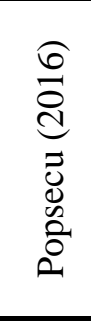 } & II-S & 1800 & 1350 & 60 & 1050 & 450 & Door & $\mathrm{P}-\mathrm{C}^{1}$ & \multirow{6}{*}{$\begin{array}{l}\text { Fully } \\
\text { wrapped } \\
\text { CFRP with } \\
\text { mechanical } \\
\text { anchor }\end{array}$} & 62.8 & 2241 & $0.330(49 \%)$ \\
\hline & II-L & 1800 & 1350 & 60 & 1050 & 900 & Door & $\mathrm{P}-\mathrm{C}$ & & 62.8 & 1487 & $0.219(26 \%)$ \\
\hline & III-S1 & 1800 & 1350 & 60 & 1050 & 450 & Door & $\mathrm{U}-\mathrm{C}^{2}$ & & 64.4 & 2178 & $0.311(42 \%)$ \\
\hline & III-S2 & 1800 & 1350 & 60 & 1050 & 450 & Door & U-C & & 64.4 & 2009 & $0.289(31 \%)$ \\
\hline & III-L1 & 1800 & 1350 & 60 & 1050 & 900 & Door & $\mathrm{U}-\mathrm{C}$ & & 64.4 & 1334 & $0.191(10 \%)$ \\
\hline & III-L2 & 1800 & 1350 & 60 & 1050 & 900 & Door & $\mathrm{U}-\mathrm{C}$ & & 64.4 & 1482 & $0.213(22 \%)$ \\
\hline \multirow{8}{*}{ 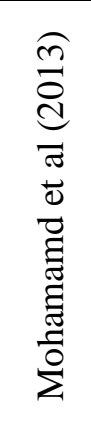 } & Wo1b & 800 & 400 & 40 & 170 & 95 & window & $\mathrm{U}-\mathrm{C}$ & \multirow{4}{*}{$\begin{array}{l}\text { EB-CFRP } \\
\text { alongside } \\
\text { of the } \\
\text { opening }\end{array}$} & 15.0 & 150 & $0.626(60 \%)$ \\
\hline & W02b & 800 & 400 & 40 & 240 & 135 & window & U-C & & 17.1 & 139 & $0.509(20 \%)$ \\
\hline & W023b & 800 & 400 & 40 & 340 & 185 & window & U-C & & 18.2 & 108 & $0.370(12 \%)$ \\
\hline & W04b & 800 & 400 & 40 & 420 & 230 & window & \multirow{2}{*}{$\frac{U-C}{U-C}$} & & 15.1 & 82 & $0.340(17 \%)$ \\
\hline & W01c & 800 & 400 & 40 & 170 & 95 & window & & \multirow{4}{*}{$\begin{array}{l}\text { EB-CFRP } \\
\text { with } 45^{0} \text { to } \\
\text { the } \\
\text { opening's } \\
\text { corners }\end{array}$} & 14.7 & 175 & $0.745(90 \%)$ \\
\hline & W02c & 800 & 400 & 40 & 240 & 135 & window & $\mathrm{U}-\mathrm{C}$ & & 15.6 & 157 & $0.628(48 \%)$ \\
\hline & W03c & 800 & 400 & 40 & 340 & 185 & window & U-C & & 16.4 & 139 & $0.529(60 \%)$ \\
\hline & W04c & 800 & 400 & 40 & 420 & 230 & window & $\mathrm{U}-\mathrm{C}$ & & 17.0 & 85 & $0.311(8 \%)$ \\
\hline
\end{tabular}

Note: ${ }^{1}$ P-C: Pre-Cracked; ${ }^{2} \mathrm{U}-\mathrm{C}$ : Un-Cracked $;{ }^{3} f_{c}^{\prime}$ : Concrete compressive strength; ${ }^{4} N_{u o}$ :Ultimate strength of RC walls 
Table 2. Properties of CFRP: 230C [Sika 2014]

\begin{tabular}{cccccc}
\hline $\begin{array}{c}\text { Areal weight } \\
\left(\mathrm{g} / \mathrm{m}^{2}\right)\end{array}$ & $\begin{array}{c}\text { Thickness } \\
(\mathrm{mm})\end{array}$ & $\begin{array}{c}\text { Density } \\
\left(\mathrm{g} / \mathrm{cm}^{3}\right)\end{array}$ & $\begin{array}{c}\text { Tensile Modulus } \\
(\mathrm{MPa})\end{array}$ & $\begin{array}{c}\text { Tensile Strength } \\
(\mathrm{MPa})\end{array}$ & $\begin{array}{c}\text { Elongation } \\
\text { at Failure } \\
(\%)\end{array}$ \\
\hline $230 \pm 10$ & 0.128 & 1.8 & 234000 & 4300 & 1.8 \\
\hline
\end{tabular}


Table 3. Location, width and length of the applied CFRP sheets

\begin{tabular}{|c|c|c|c|c|}
\hline \multirow{2}{*}{$\begin{array}{l}\text { CFRP } \\
\text { layout }\end{array}$} & \multirow{2}{*}{$\begin{array}{l}\text { Location in relation to edges of the opening / } \\
\text { (confinement, tension or compression side) }\end{array}$} & \multirow{2}{*}{$\begin{array}{l}\text { Width } \\
(\mathrm{mm})\end{array}$} & \multicolumn{2}{|c|}{ Length (mm) } \\
\hline & & & Individual & Total \\
\hline NF & - & - & - & - \\
\hline $\mathrm{DF}$ & In corner $\left(45^{0}\right) /$ tension & 105 & 450 & 1800 \\
\hline $\mathrm{AF}$ & Along $\left(0 / 90^{\circ}\right) /$ tension & 105 & 770 & 3080 \\
\hline WF & $\begin{array}{c}\text { In corner }\left(45^{\circ}\right) \text { and wrapped }\left(0 / 90^{\circ}\right) / \text { tension and } \\
\text { compression }\end{array}$ & 105 & 450 and 440 & 5320 \\
\hline $\mathrm{CF}$ & In corner $\left(45^{\circ}\right)$ and along $\left(0 / 90^{\circ}\right) /$ tension & 105 & 450 and 770 & 4880 \\
\hline $\mathrm{PF}$ & Along $\left(90^{\circ}\right) /$ tension & 105 & 1480 & 2960 \\
\hline MF & In corner $\left(45^{\circ}\right)$ and along $\left(90^{\circ}\right) /$ tension & 105 & 1480,1380 & 4240 \\
\hline FWF & Fully wrapped around opening / confinement & 450 & 850 & 1700 \\
\hline
\end{tabular}


Table 4. Ultimate load of RC wall panels

\begin{tabular}{|c|c|c|c|c|c|c|c|}
\hline Wall designation & $\begin{array}{l}\text { Curing } \\
\text { duration }\end{array}$ & $\begin{array}{c}f_{c}^{\prime 1} \\
(\mathrm{MPa})\end{array}$ & $\begin{array}{c}t_{w}^{2} \\
(\mathrm{~mm})\end{array}$ & $N_{\text {ио }}(\mathrm{kN})$ & $\begin{array}{c}N_{u o}(\mathrm{OW}) \\
N_{u o}(\mathrm{TW} 3 \mathrm{~S}) \\
\text { or } \\
N_{u o}(\mathrm{OW}) \\
N_{u o}(\mathrm{TW} 4 \mathrm{~S})\end{array}$ & $\begin{array}{l}\text { Axial strength ratio } \\
N_{u o} / f^{\prime}{ }_{c} . L_{w} \cdot t_{w}\end{array}$ & $\begin{array}{l}\text { Efficiency [Increase of ultimate } \\
\left.\text { load }(\%) \text { to } L_{\text {CFRP }}(\mathrm{m})\right]\end{array}$ \\
\hline OW-NF & 86 & 54.7 & 40.0 & 266 & - & 0.101 & - \\
\hline OW-DF & 113 & 55.0 & 40.0 & 309 & - & $0.117(15.5 \%)$ & 8.6 \\
\hline OW-AF & 86 & 54.7 & 40.0 & 336 & - & $0.128(26.2 \%)$ & 8.5 \\
\hline OW-WF & 73 & 62.6 & 43.5 & 415 & - & $0.127(25.4 \%)$ & 4.8 \\
\hline OW-CF & 73 & 62.6 & 46.0 & 559 & - & $0.162(59.7 \%)$ & 12.2 \\
\hline OW-PF & 84 & 64.9 & 40.0 & 360 & - & $0.1165(14.0 \%)$ & 4.8 \\
\hline TW3S-NF & 82 & 60.0 & 40.0 & 440 & 0.7 & 0.153 & - \\
\hline TW3S-DF & 68 & 57.0 & 44.0 & 589 & 0.6 & $0.196(28.2 \%)$ & 15.7 \\
\hline TW3S-AF & 68 & 58.5 & 43.0 & 650 & 0.6 & $0.215(40.8 \%)$ & 13.2 \\
\hline TW3S-WF & 74 & 62.3 & 46.0 & 700 & 0.6 & $0.204(33.2 \%)$ & 6.3 \\
\hline TW3S-CF & 68 & 62.3 & 40.0 & 643 & 0.8 & $0.215(40.8 \%)$ & 8.4 \\
\hline TW3S-MF & 84 & 65.0 & 40.0 & 633 & - & $0.203(32.9 \%)$ & 7.8 \\
\hline TW3S-FWF & 69 & 58.4 & 40.0 & 441 & - & $0.157(3.0 \%)$ & 1.8 \\
\hline TW4S-NF & 67 & 57.6 & 40.0 & 647 & 0.4 & 0.234 & - \\
\hline TW4S-DF & 67 & 57.6 & 40.0 & 766 & 0.4 & $0.277(18.4 \%)$ & 10.2 \\
\hline TW4S-AF & 67 & 56.2 & 40.0 & 753 & 0.5 & $0.279(19.3 \%)$ & 6.2 \\
\hline TW4S-WF & 75 & 64.7 & 40.0 & 894 & 0.4 & $0.288(23.0 \%)$ & 4.3 \\
\hline TW4S-CF & 75 & 63.2 & 40.0 & 887 & 0.6 & $0.293(24.9 \%)$ & 5.1 \\
\hline
\end{tabular}

Note: ${ }^{1} f_{c}^{\prime}$ : Concrete compressive strength; ${ }^{2} t_{w}:$ Wall panel thickness; ${ }^{3} N_{u o}$ : Ultimate strength of RC walls 


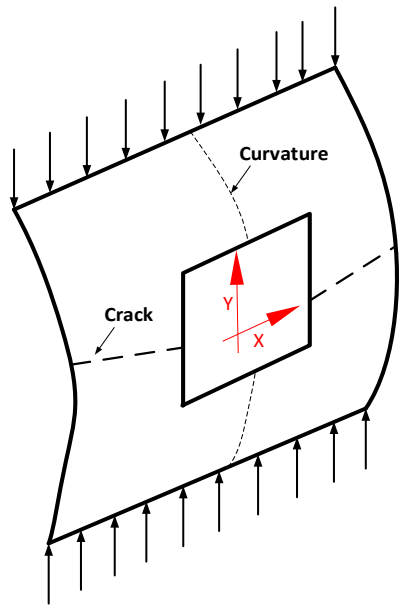

(a) OW

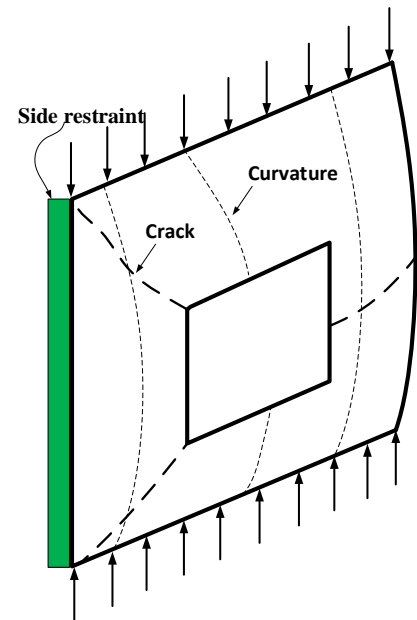

(b) TW3S

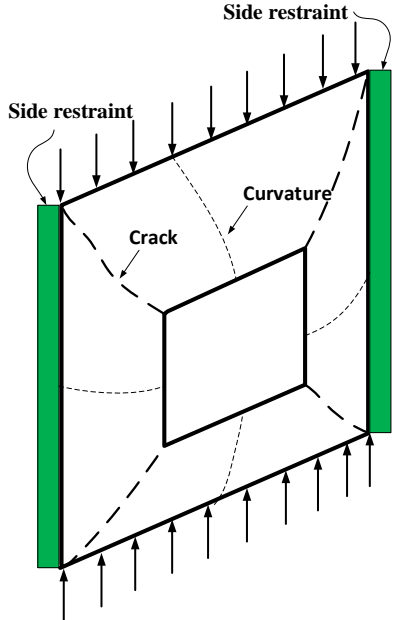

(c) TW4S

Fig. 1. Walls with and without side supports 


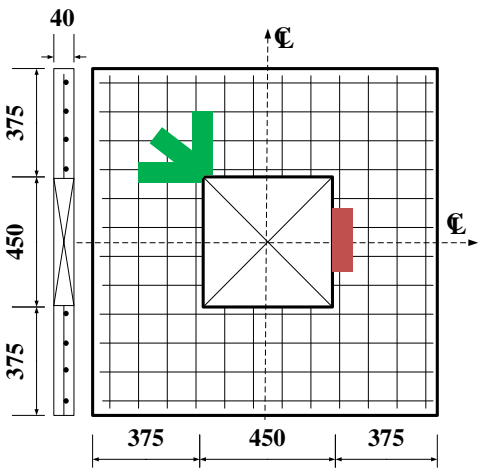

(a) $\mathrm{NF}$

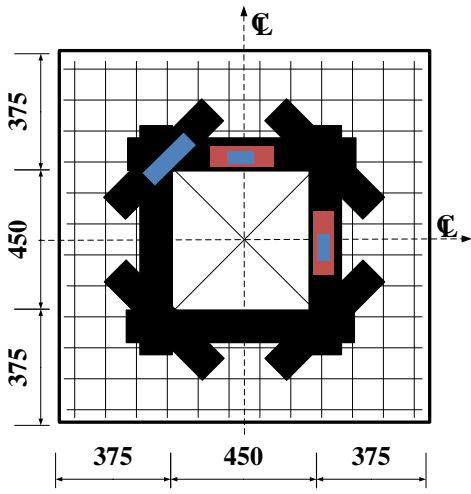

(d) $\mathrm{CF}$

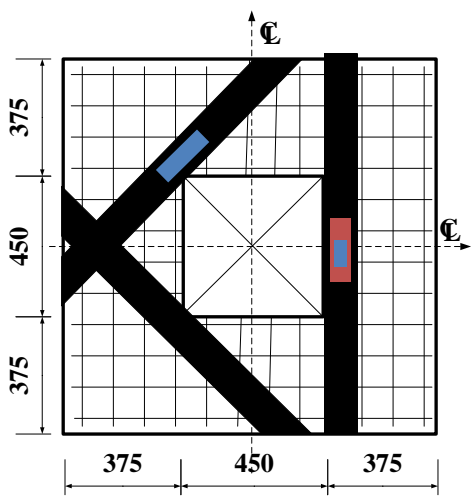

(f) $\mathrm{MF}$

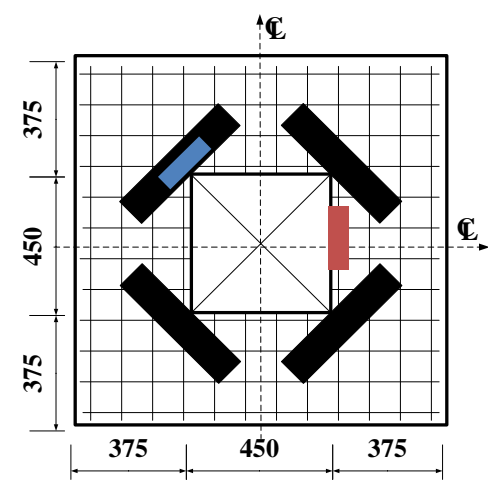

(b) $\mathrm{DF}$

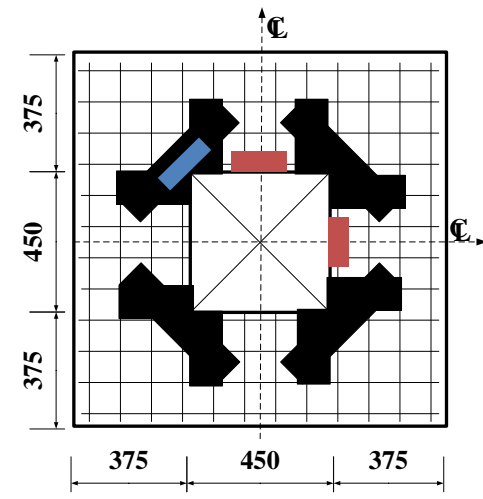

(e) WF

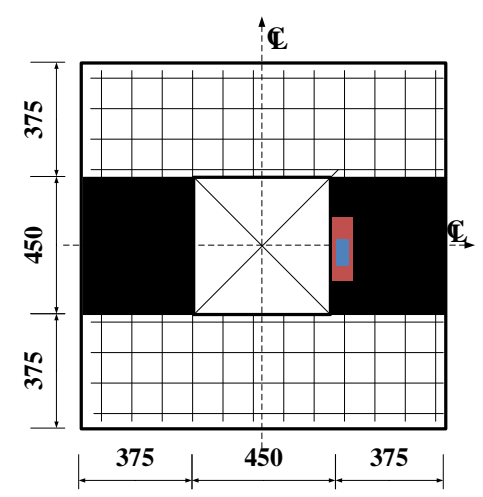

(g) FWF

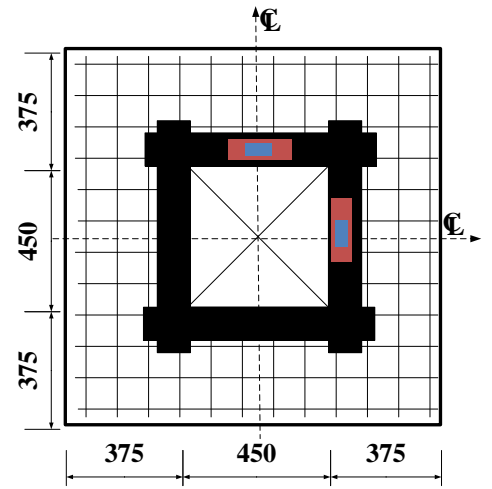

(c) $\mathrm{AF}$

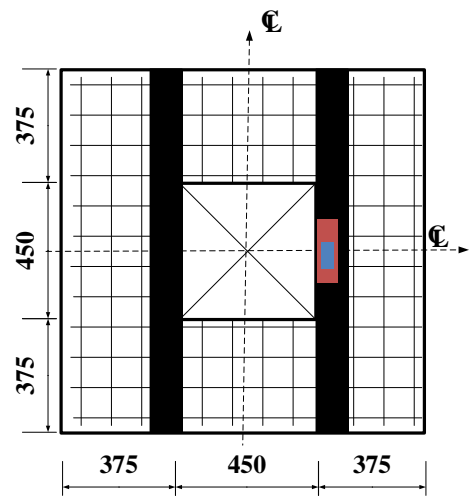

(f) $\mathrm{PF}$

\section{Legend}

\begin{tabular}{l}
\hline Strain gauge - concrete \\
Strain gauge - CFRP \\
Rosette strain gauge - concrete
\end{tabular}

Fig. 2. RC wall panels with/without CFRP layouts and strain gauges (all dimensions are in mm) 


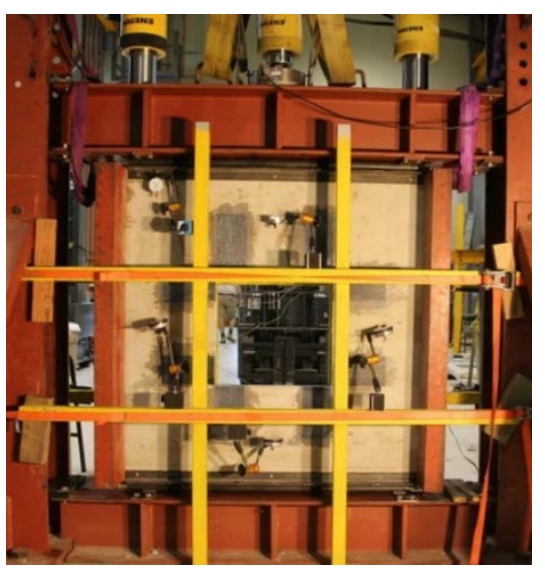

(a) Protective shield and dial gauge placement for TW4S-WF

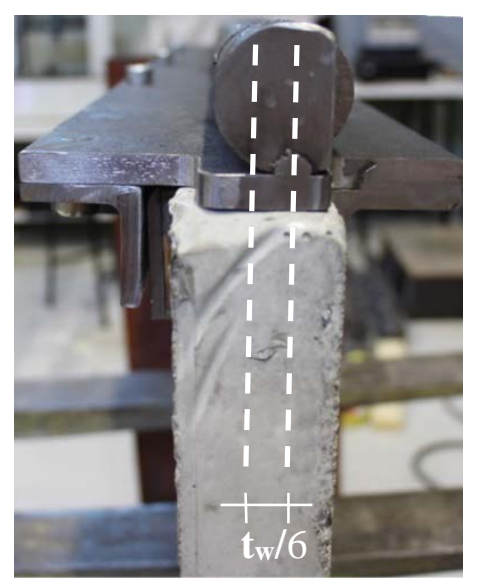

(b) Top and bottom restraint

Fig. 3. Test frame arrangement

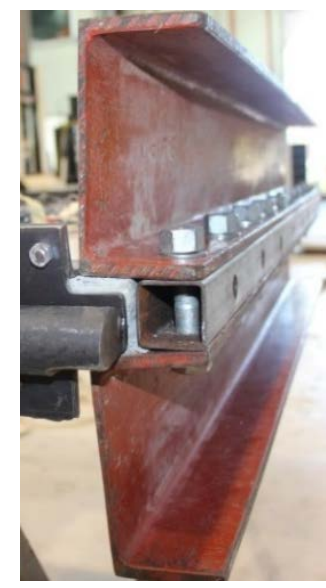

(c) Top view of side restraint 


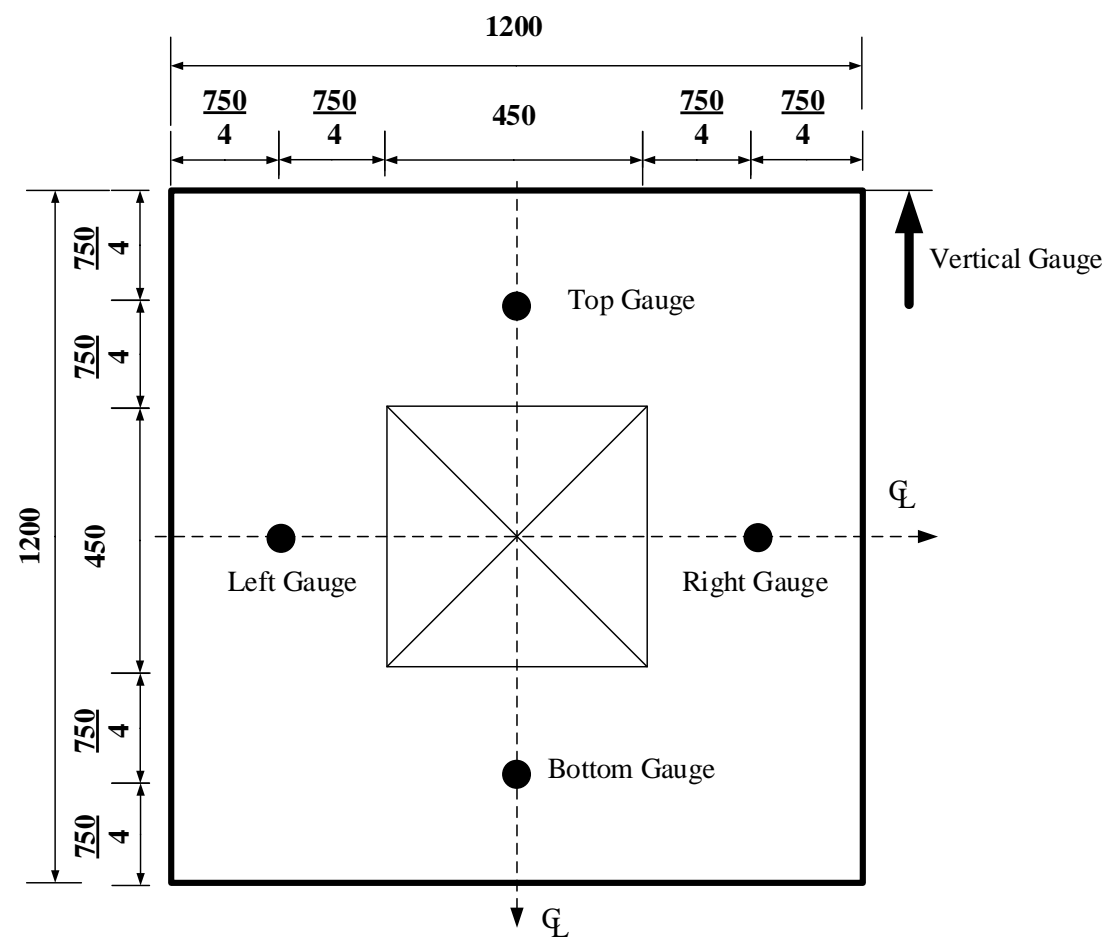

Fig. 4. Typical dial gauge locations on wall panels on the compression side (all dimensions are in $\mathrm{mm}$ ) 


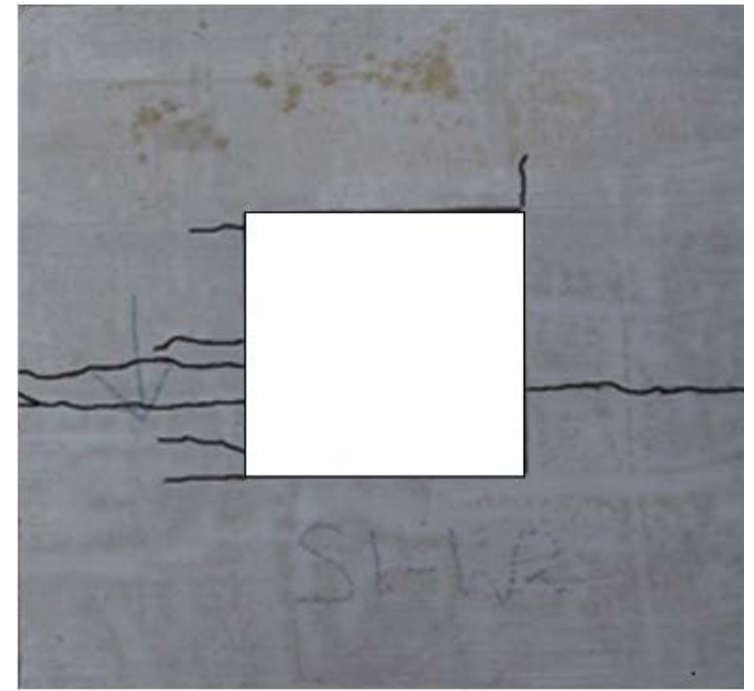

(a) OW-NF

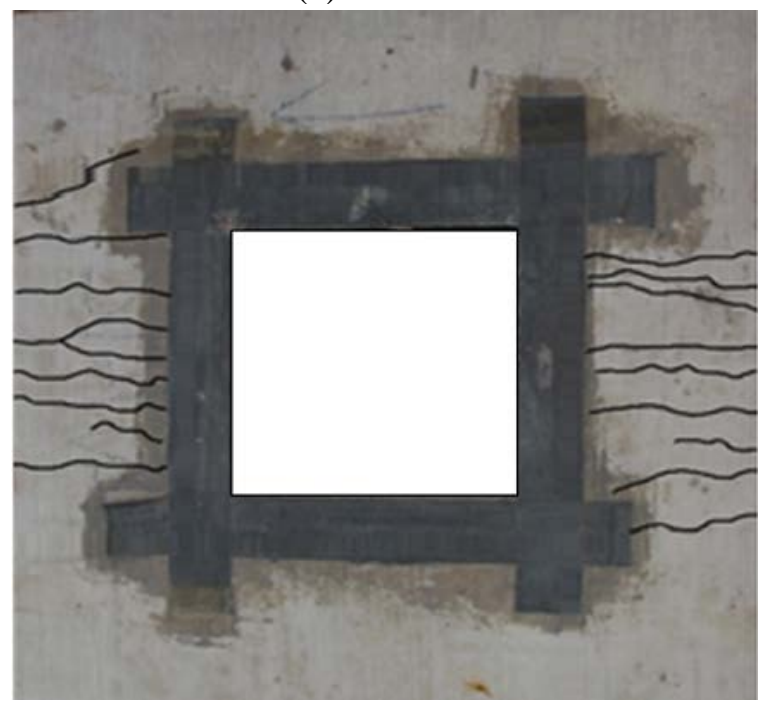

(c) OW-AF

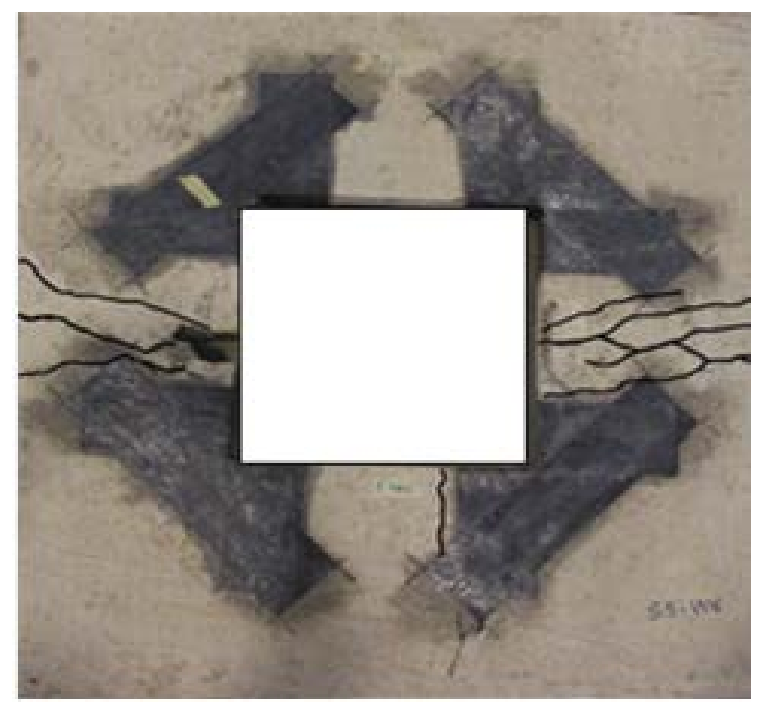

(e) OW-WF

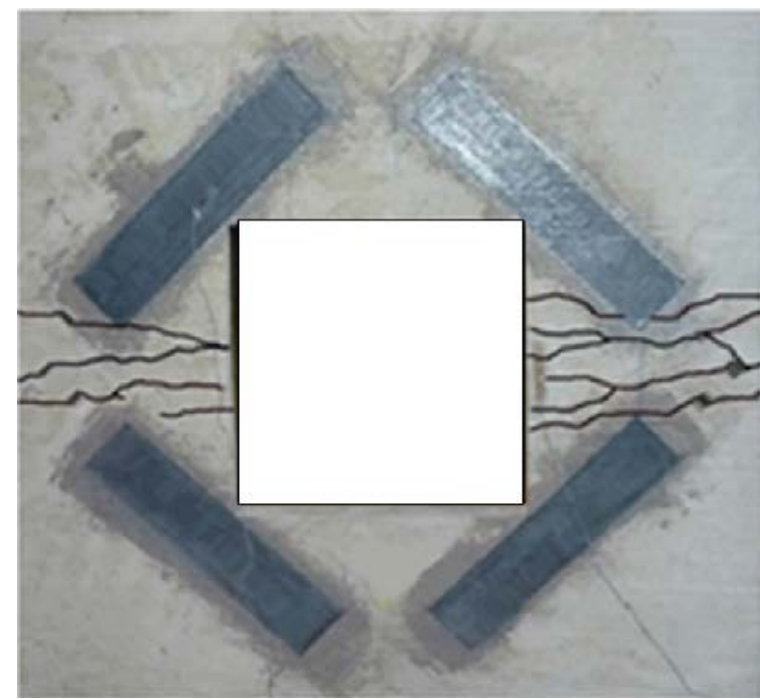

(b) OW-DF

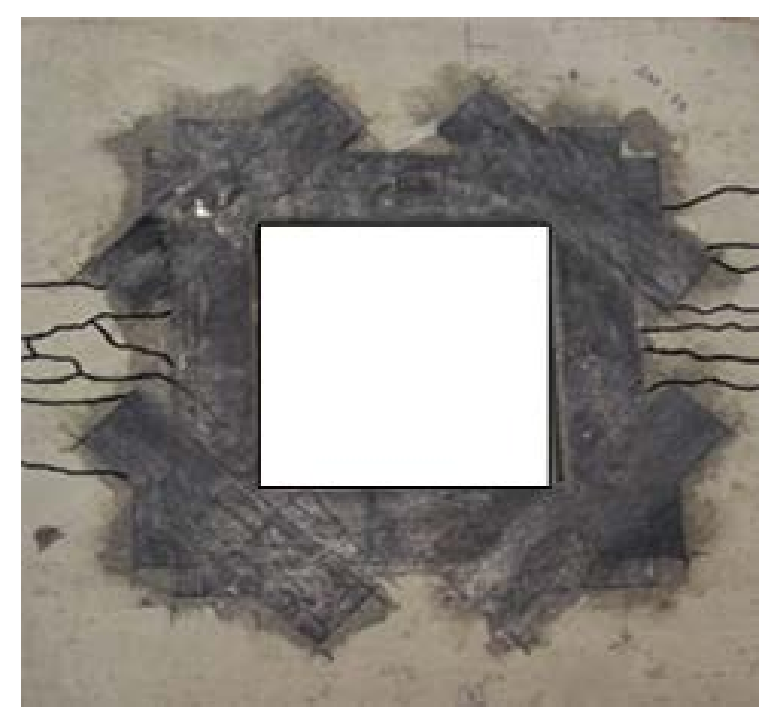

(d) OW-CF

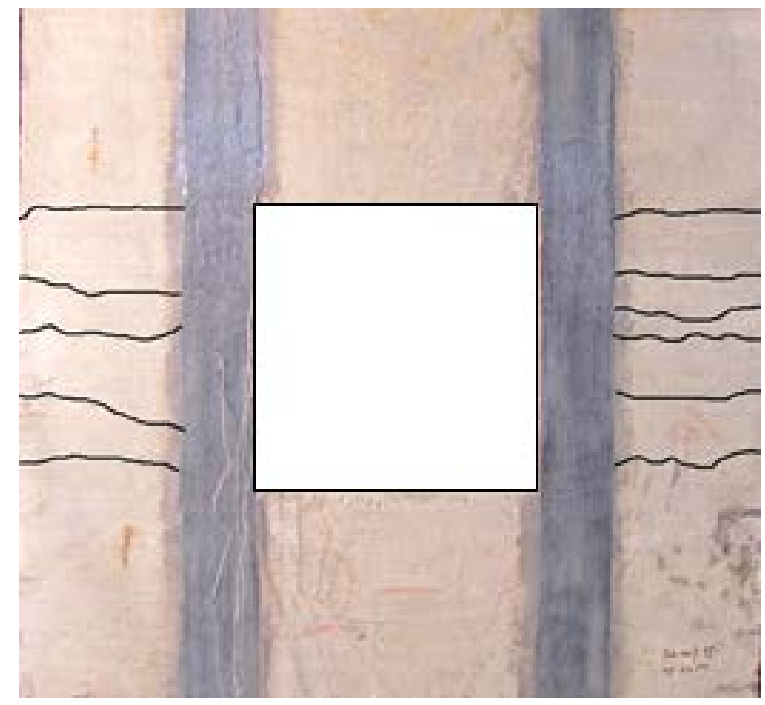

(f) OW-PF

Fig. 5. Crack patterns on tension side of walls with OW 


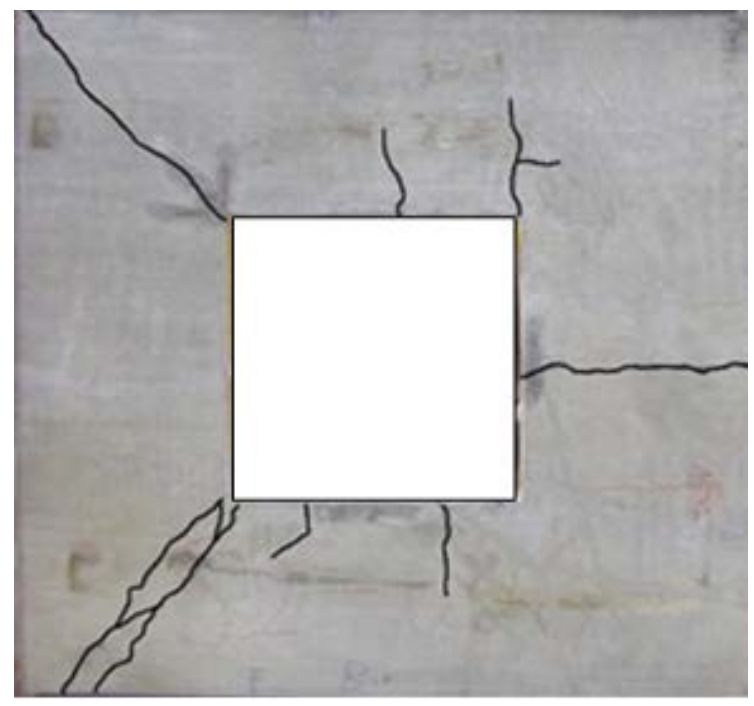

(a) TW3S-NF

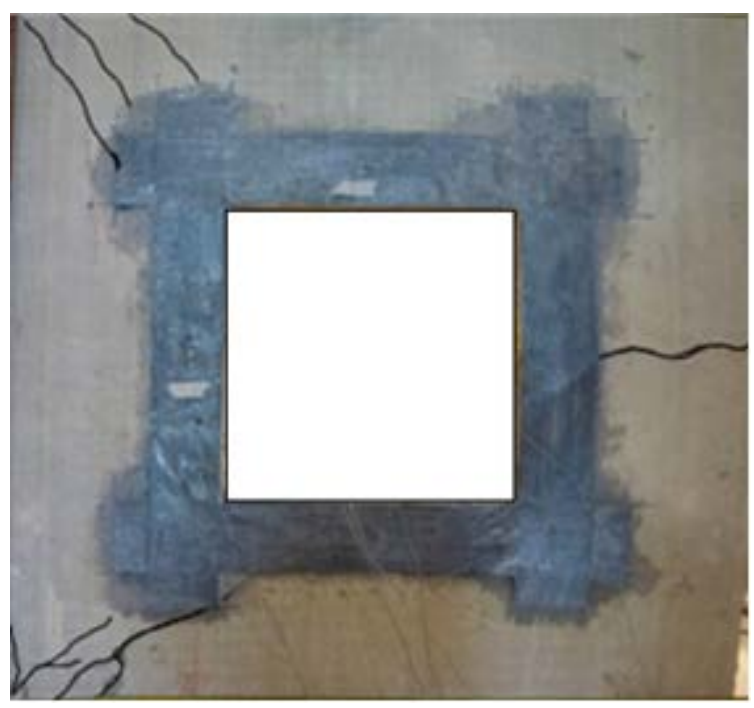

(c) TW3S-AF

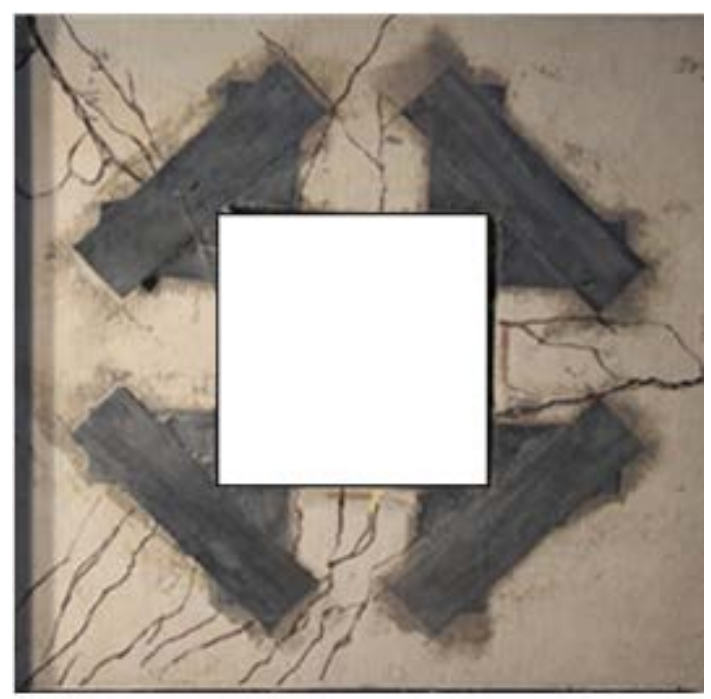

(e) TW3S-WF

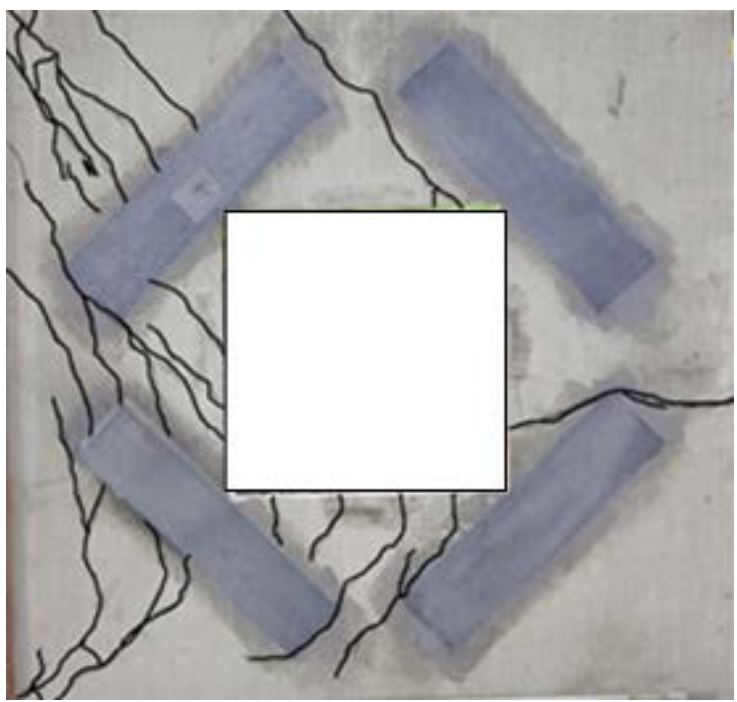

(b) TW3S-DF

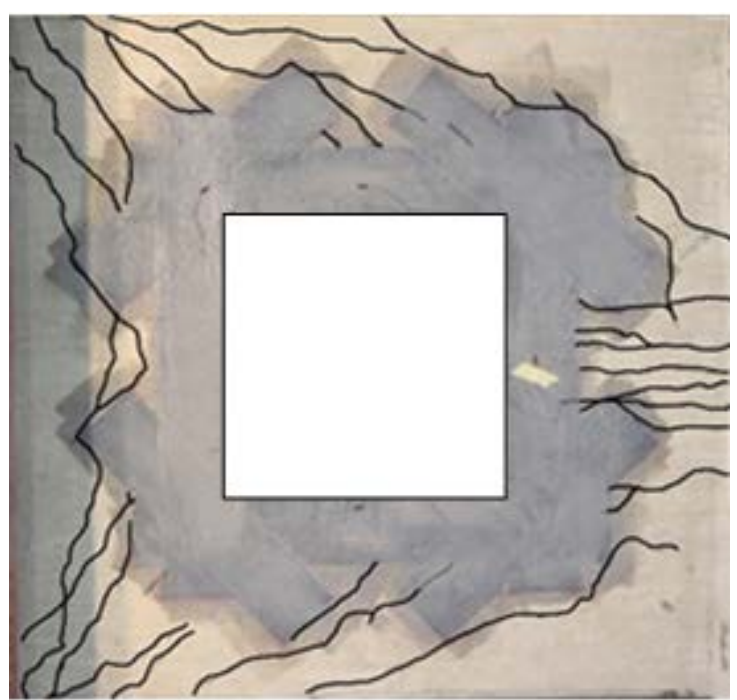

(d) TW3S-CF

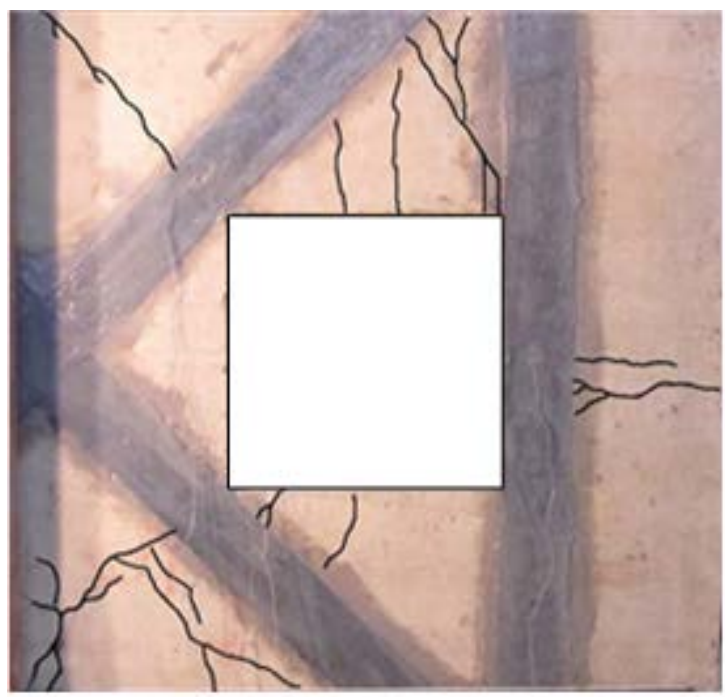

(f) TW3S-MF

Fig. 6. Crack pattern on tension side of walls with TW3S 


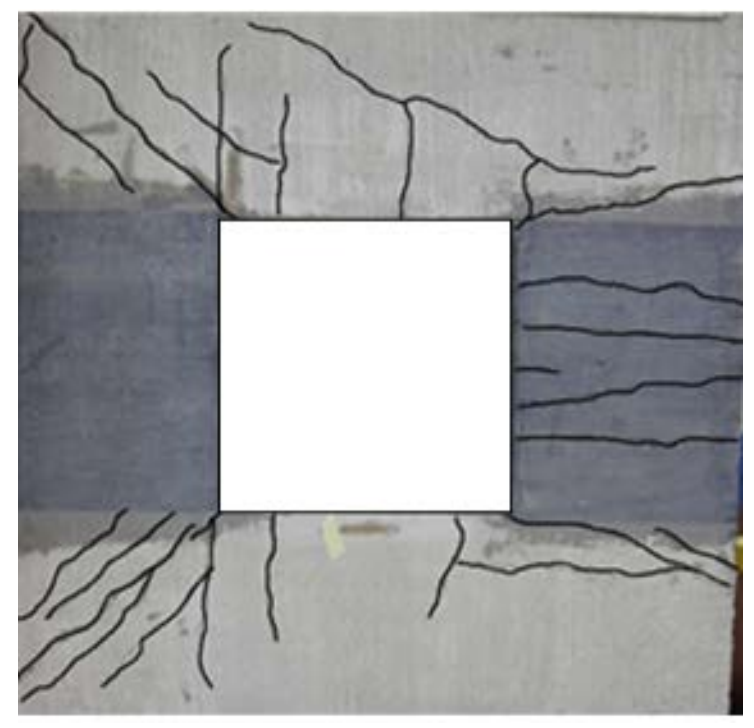

(g) TW3S-FWF

Fig. 6 (continued). Crack patterns on tension side of wall with TW3S 


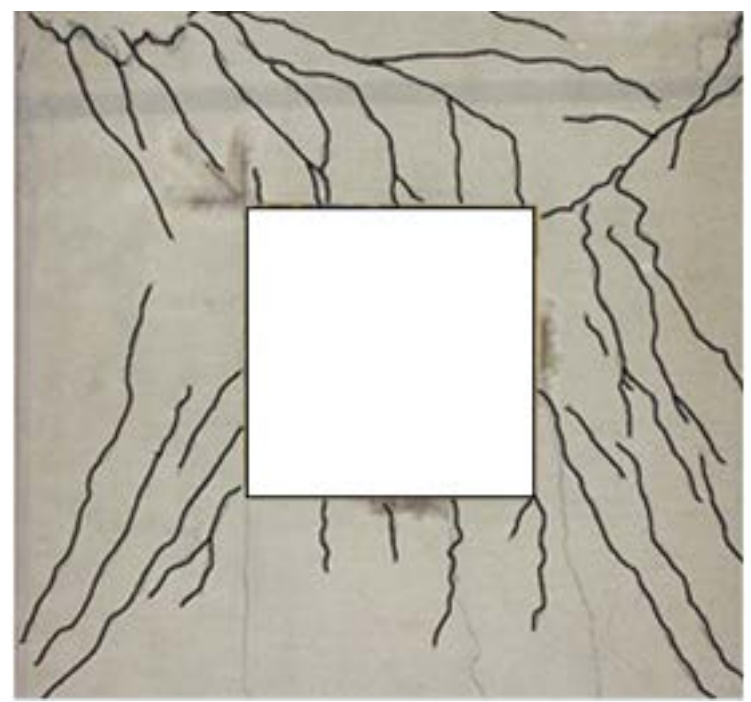

(a) TW4S-NF

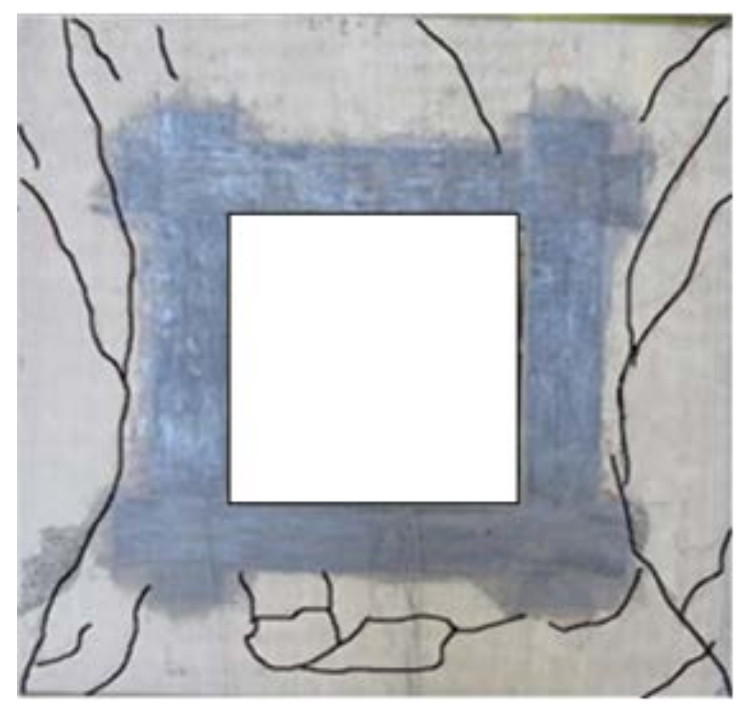

(c) TW4S-AF

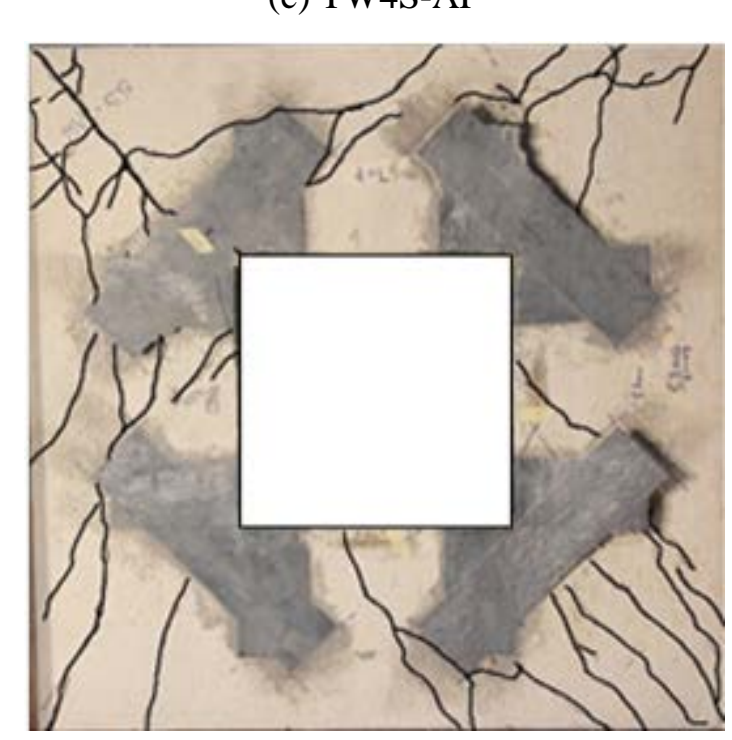

(e) TW4S-WF

Fig. 7. Crack patterns on tension side of walls with TW4S

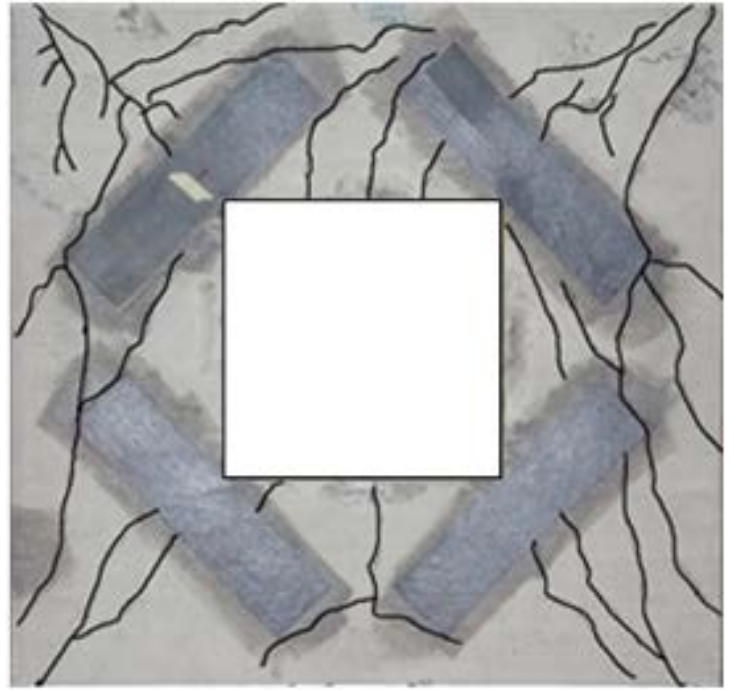

(b) TW4S-DF

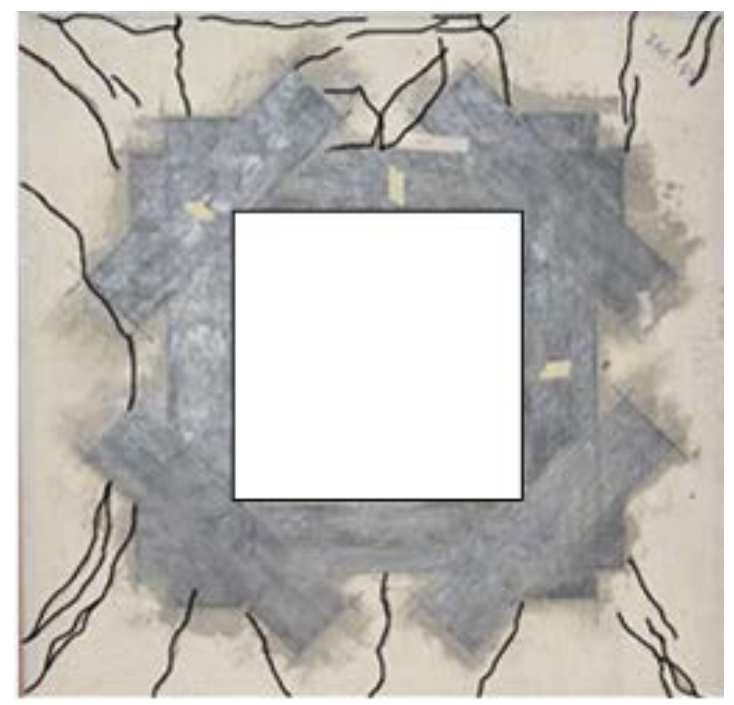

(d) TW4S-CF 


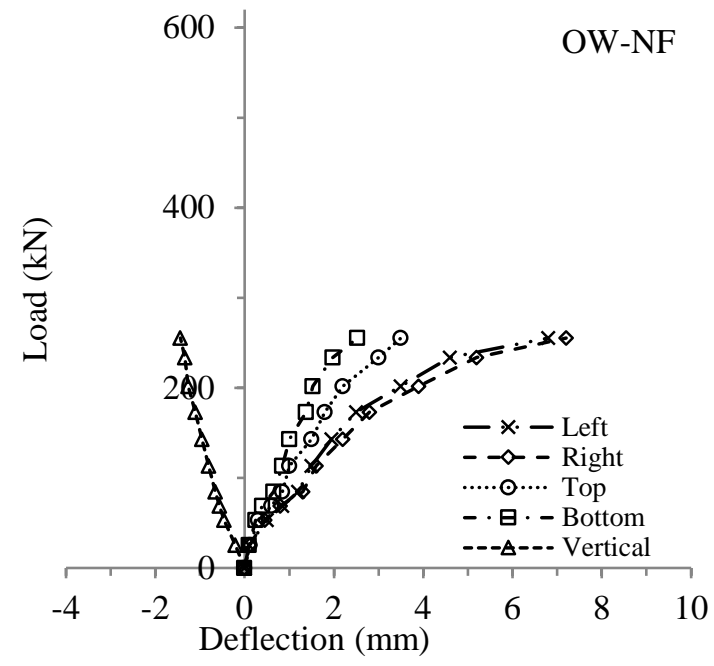

(a) OW-NF

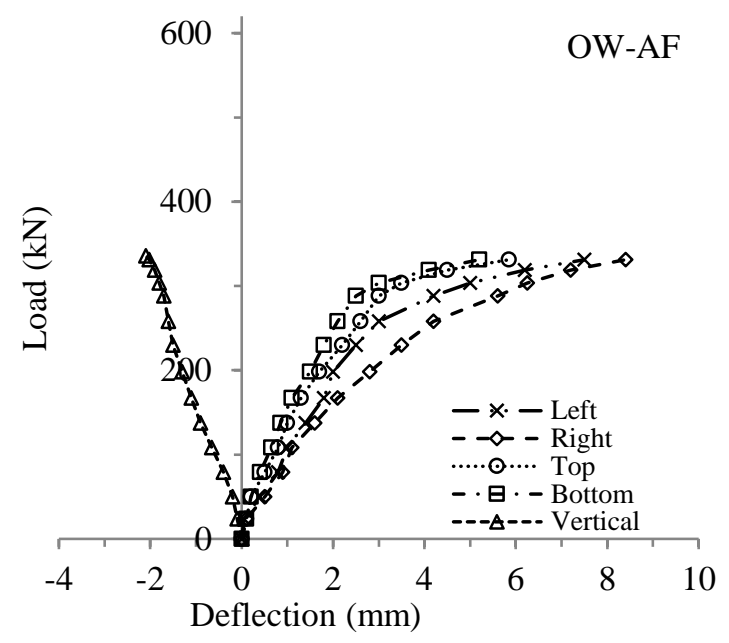

(c) OW-AF

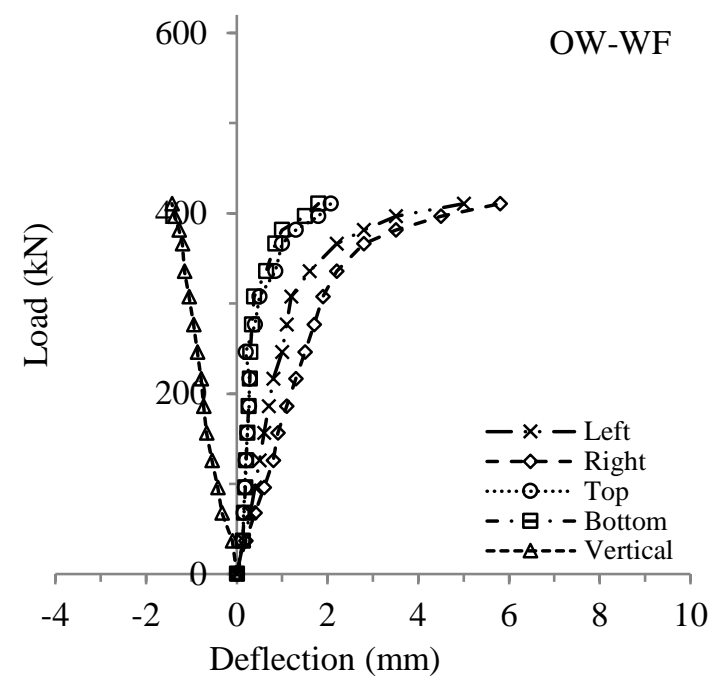

(e) OW-WF

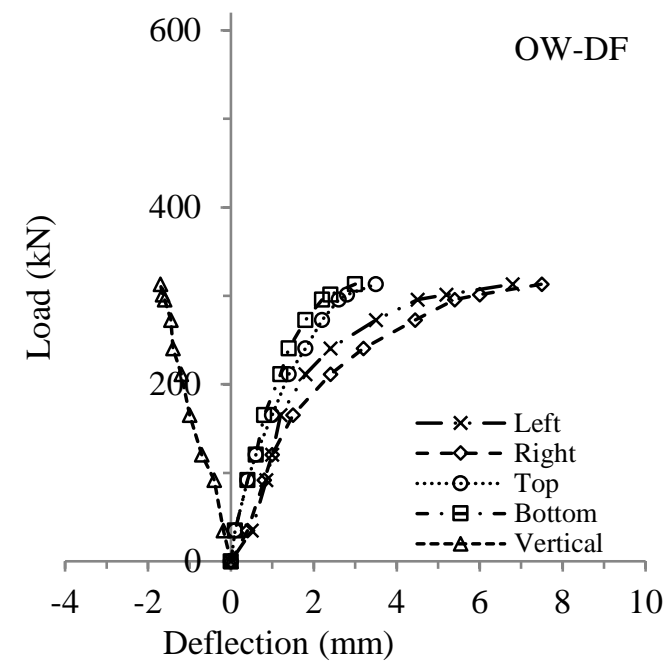

(b) OW-DF

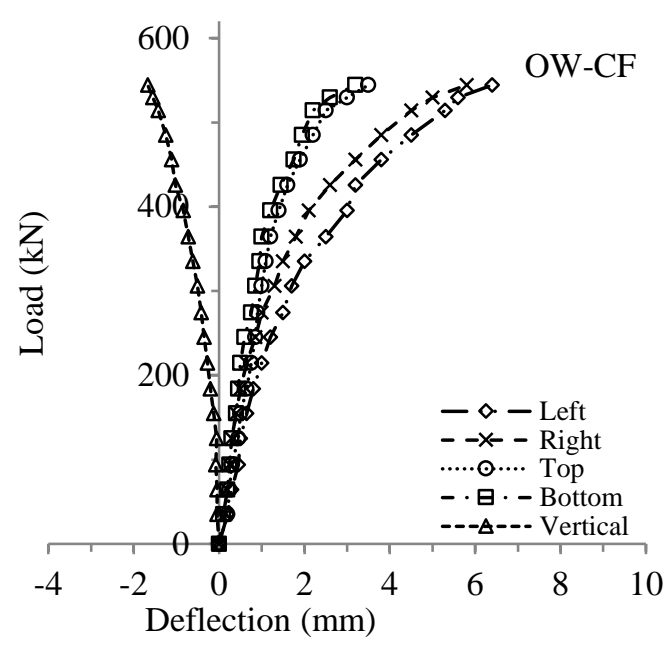

(d) OW-CF

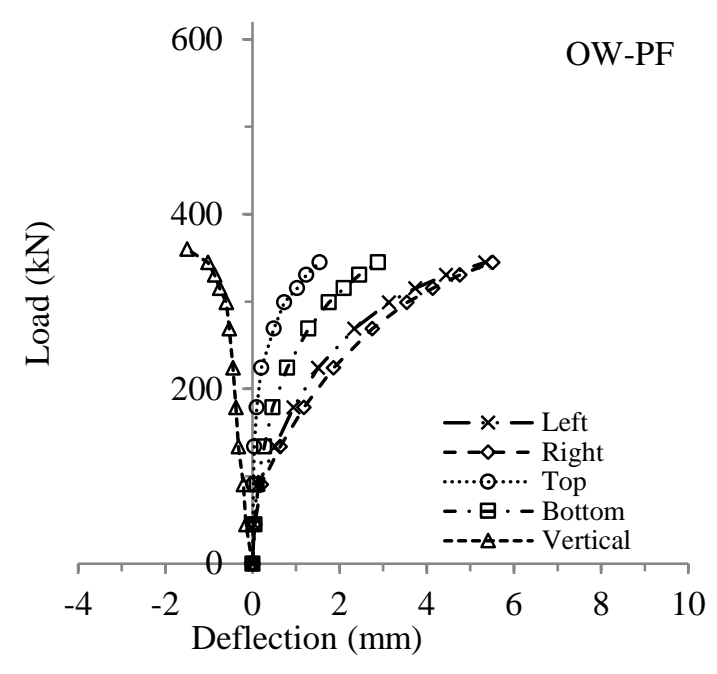

(f) OW-PF

Fig. 8. Load versus out-of-plane and in-plane deflection curves of walls with OW (refer to Fig. 4 for gauge locations) 


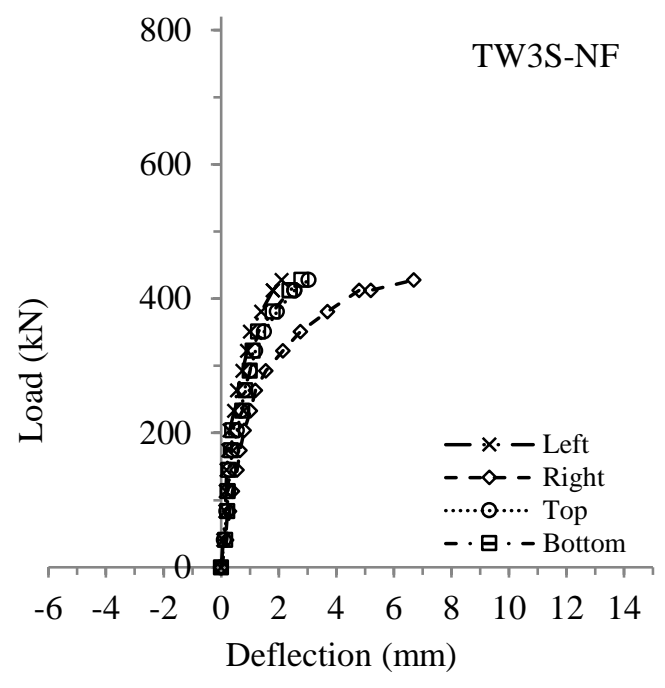

(a) TW3S-NF

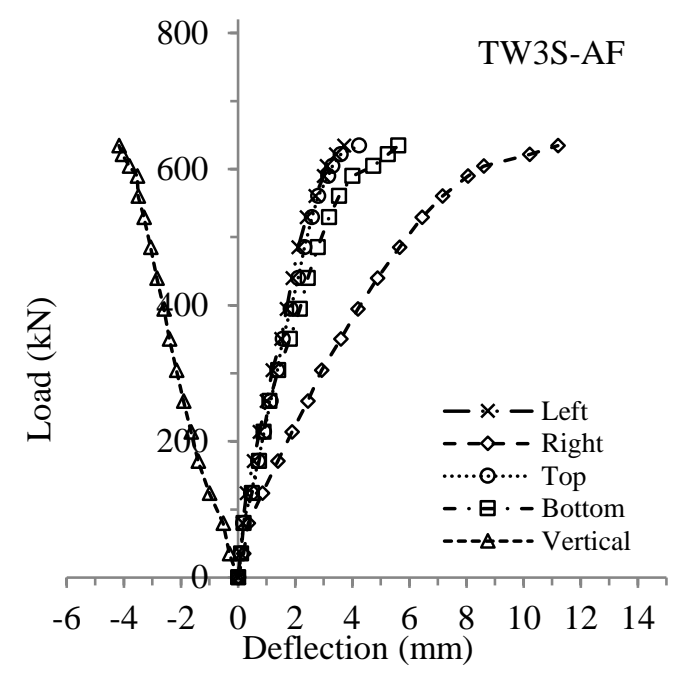

(c) TW3S-AF

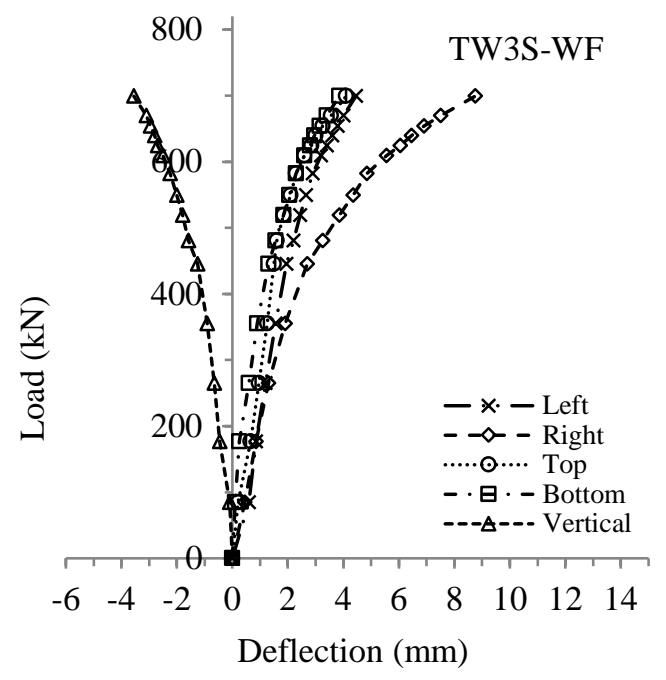

(e) TW3S-WF

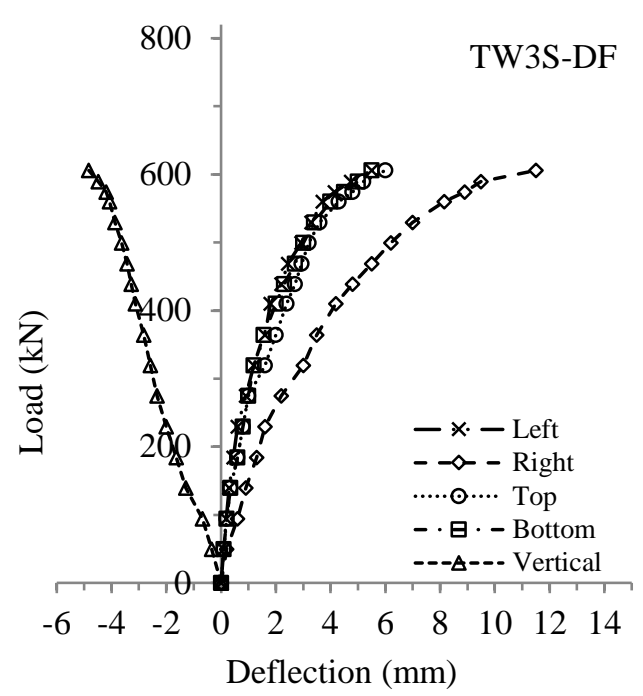

(b) TW3S-DF

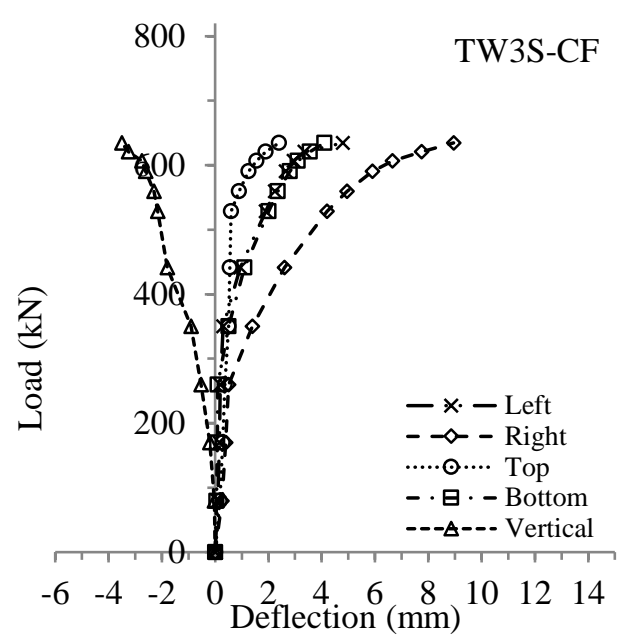

(d) TW3S-CF

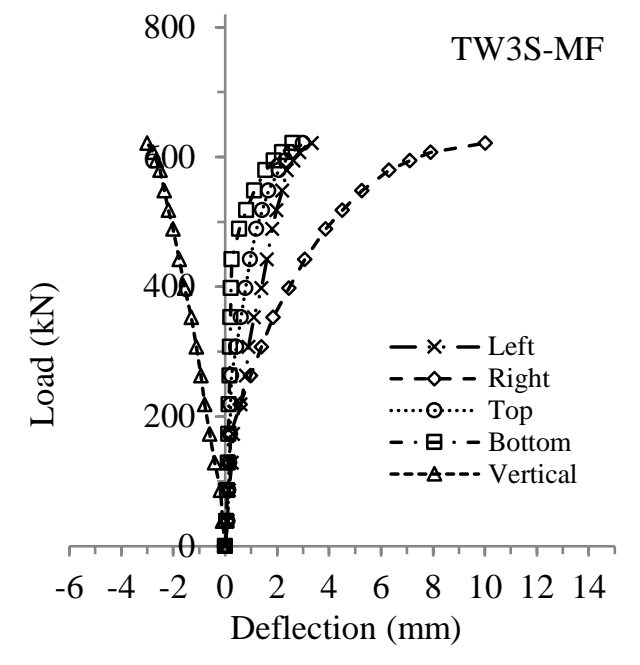

(f) TW3S-MF

Fig. 9. Load versus out-of-plane and in-plane deflection curves of walls with (refer to Fig. 4 for gauge locations) 


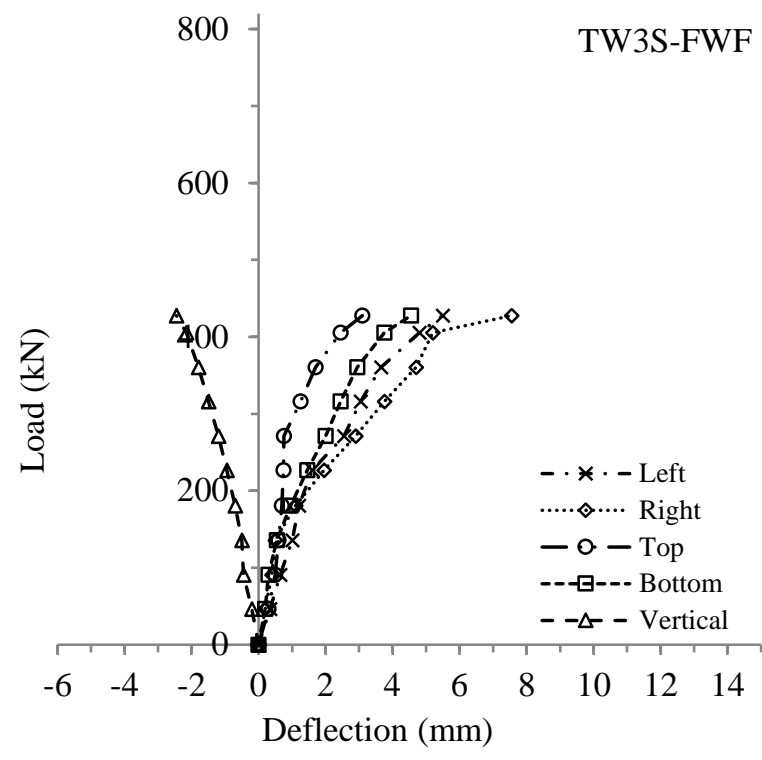

(g) TW3S-FWF

Fig. 9 (continued). Load versus out-of-plane and in-plane deflection curves of walls with TW3S (refer to Fig. 4 for gauge locations) 


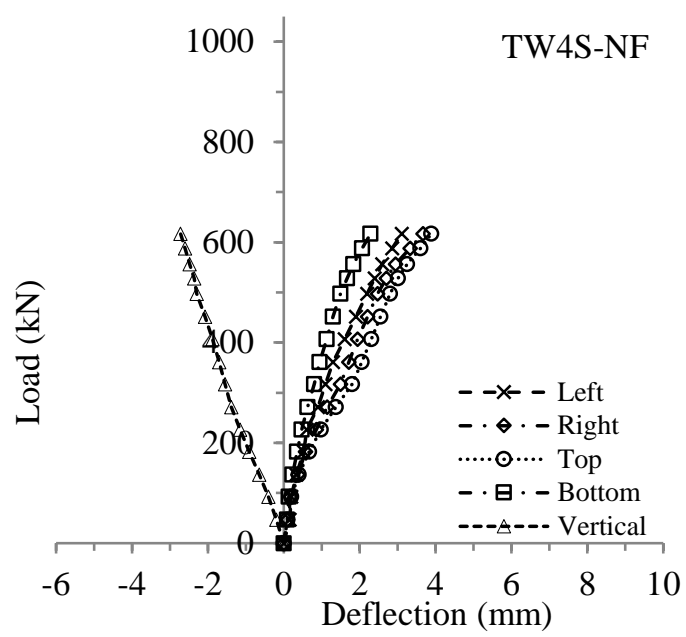

(a) TW4S-NF

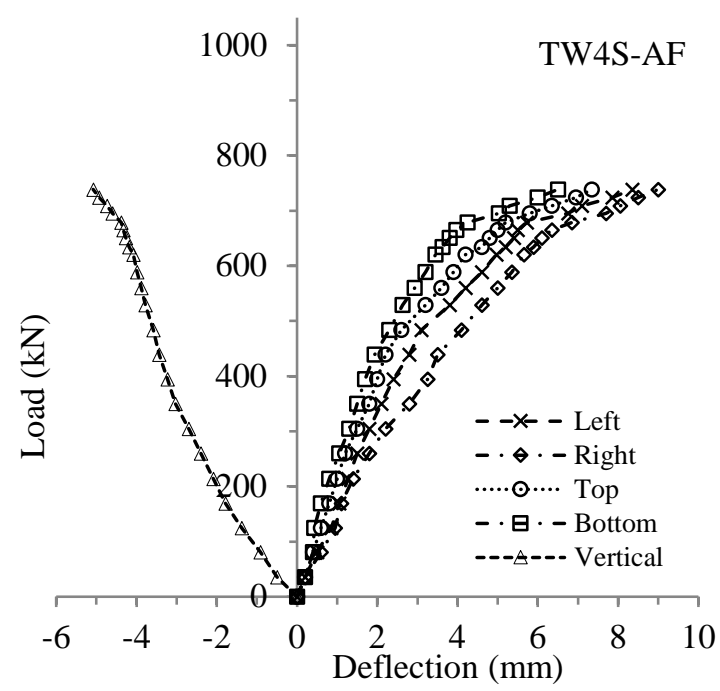

(c) TW4S-AF

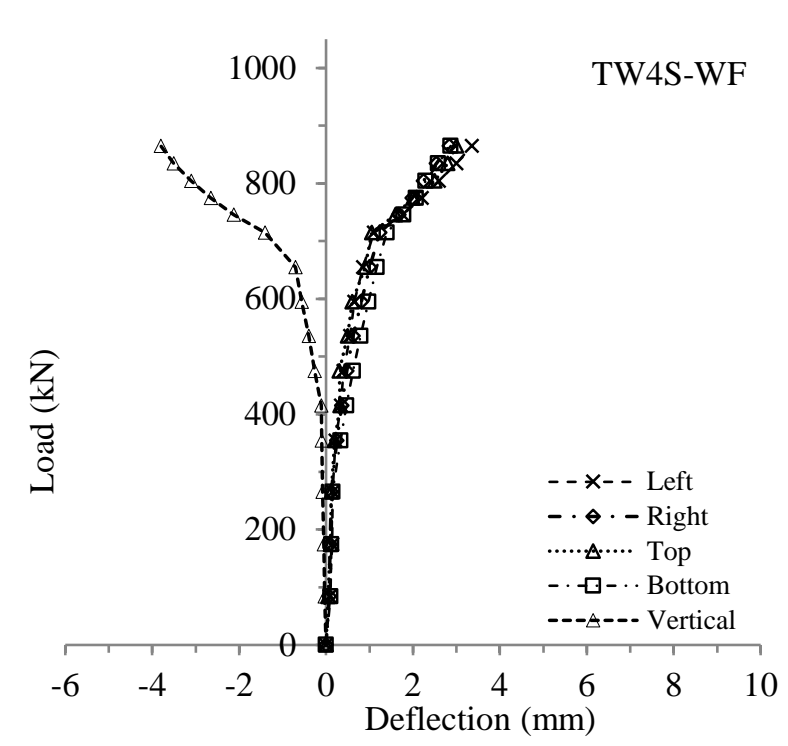

(e) TW4S-WF

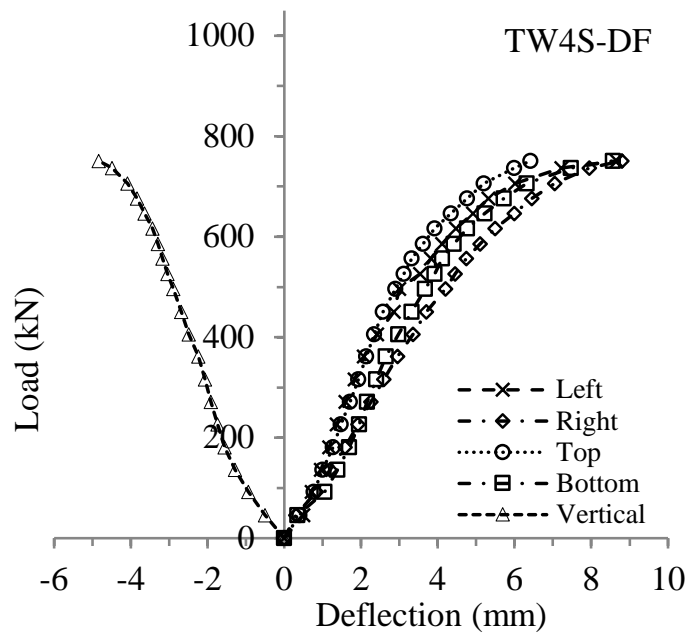

(b) TW4S-DF

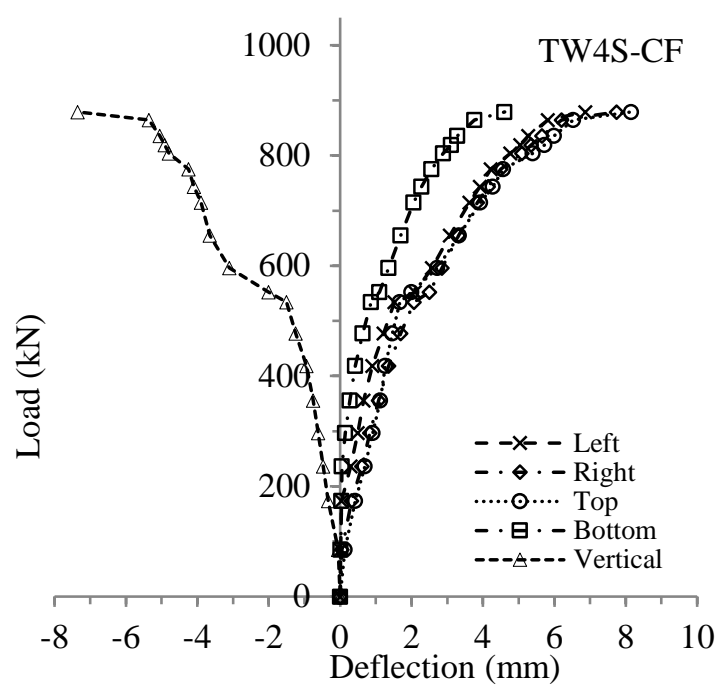

(d) TW4S-CF

Fig. 10. Load versus out-of-plane and in-plane deflection curves of walls with TW4S (refer to Fig. 4 for gauge locations) 


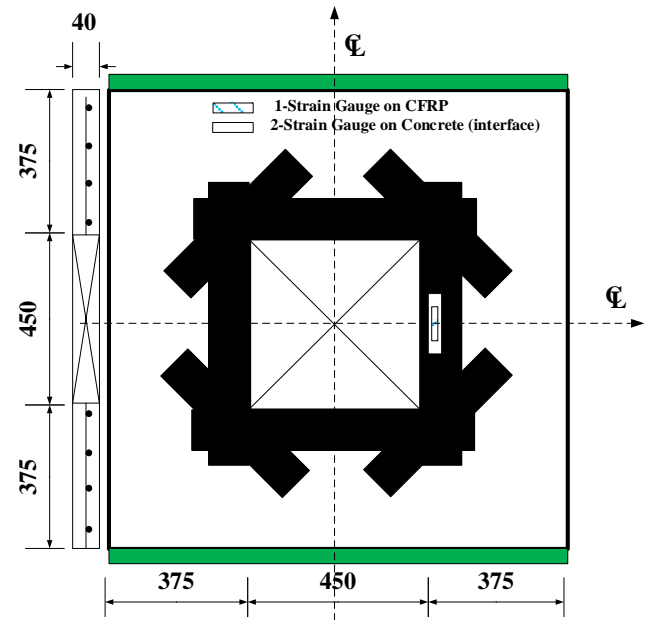

Fig. 11.. Location of strain gauges on top of CFRP and concrete (interface) of wall OW-CF 


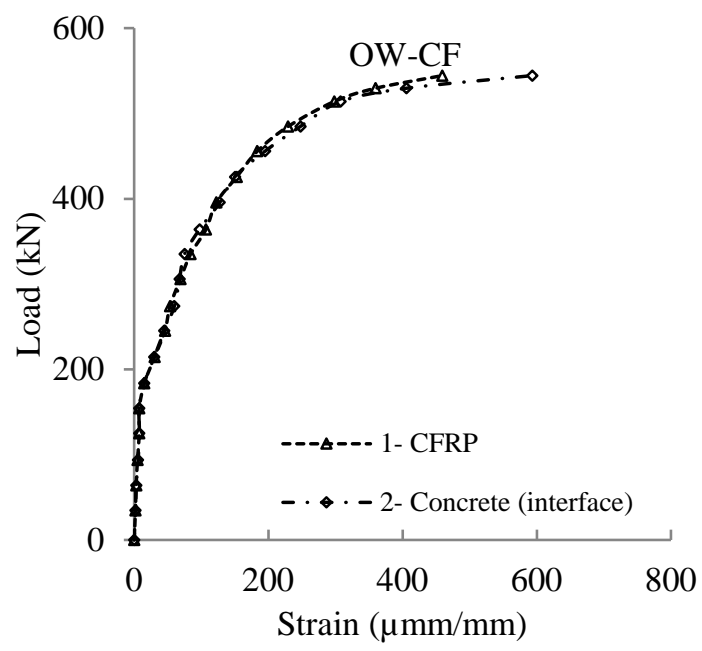

Fig. 12. Load versus strain curves of wall OW-CF 


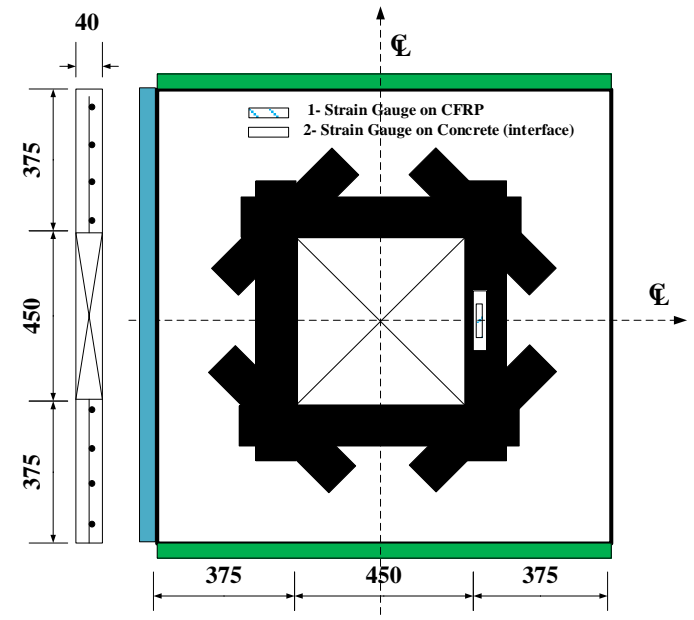

Fig. 13. Location of strain gauges on top of CFRP and concrete (interface) for wall TW3S-CF 


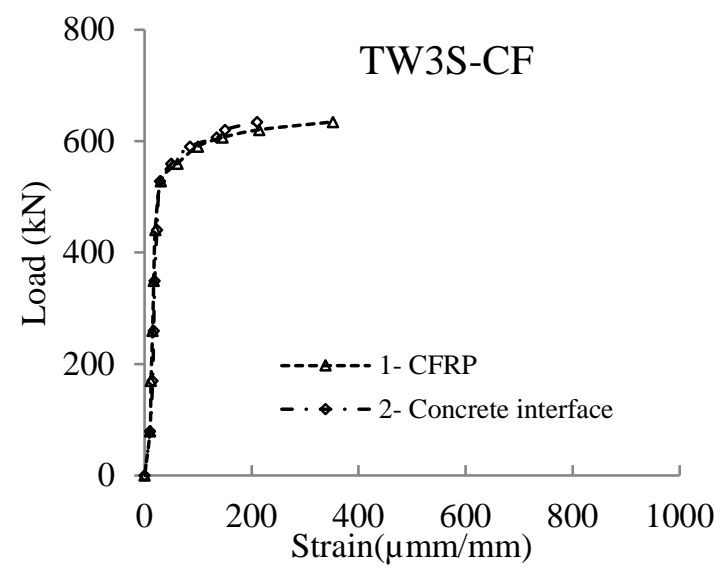

Fig. 14. Load versus strain curves of wall TW3S-CF 


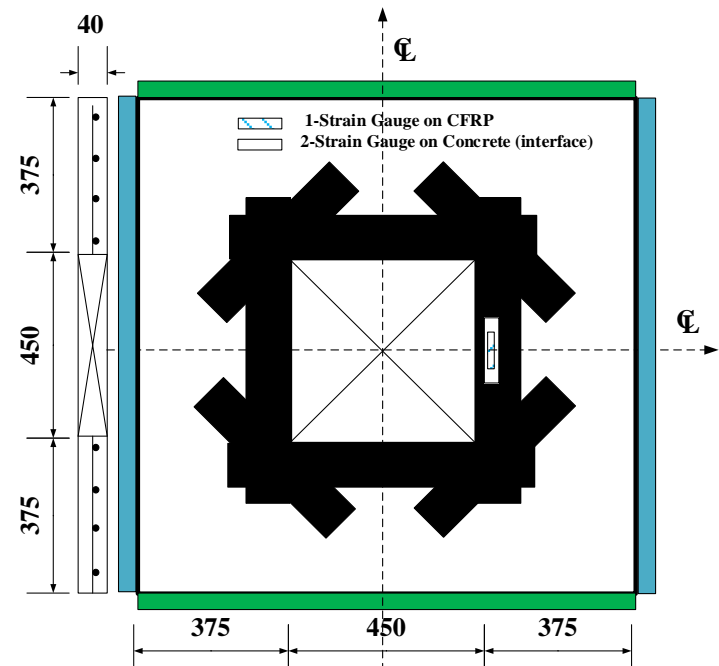

Fig. 15. Location of strain gauges on top of CFRP and concrete (interface) for wall TW4S-CF 


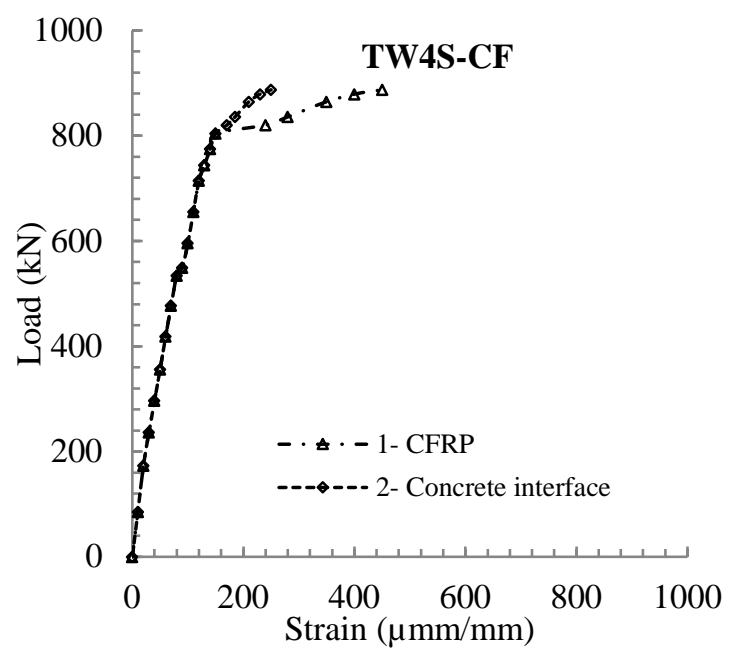

Fig. 16. Load versus strain curves of wall TW4S-CF 


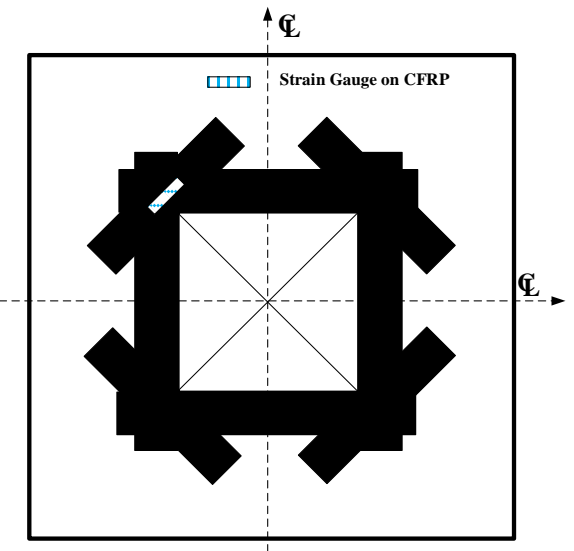

Fig. 17. Location of strain gauge on top of CFRP for walls with CF layout 


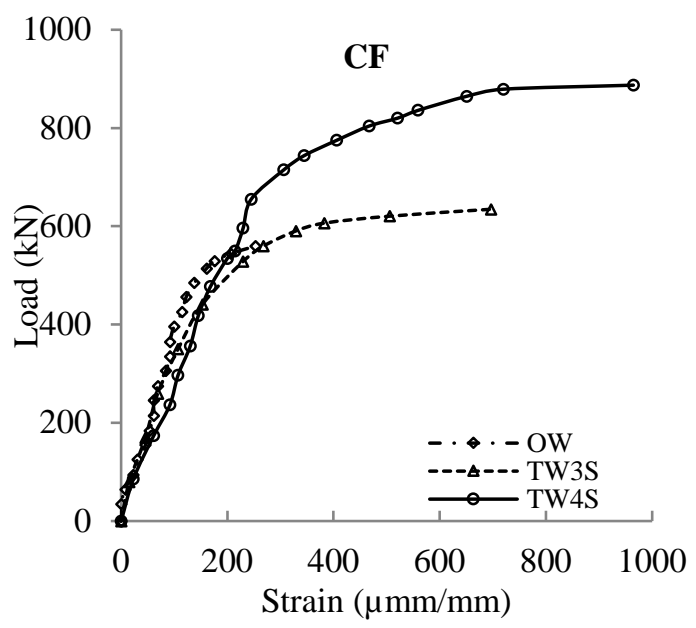

Fig. 18. Load versus strain curves of walls with CF layout 


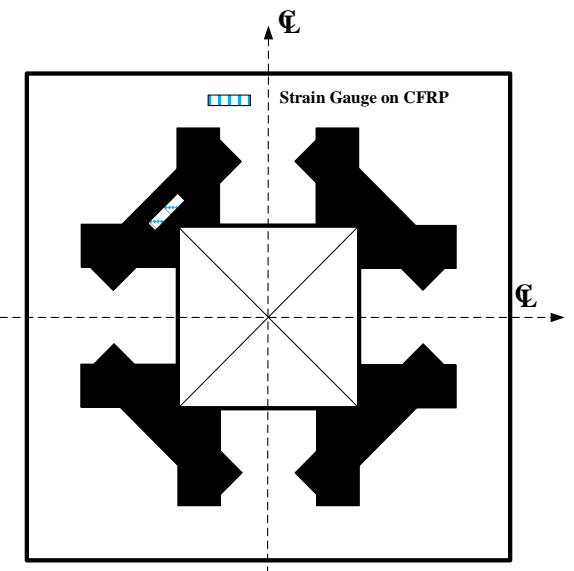

Fig. 19. Location of strain gauge on CFRP for walls with WF layout 


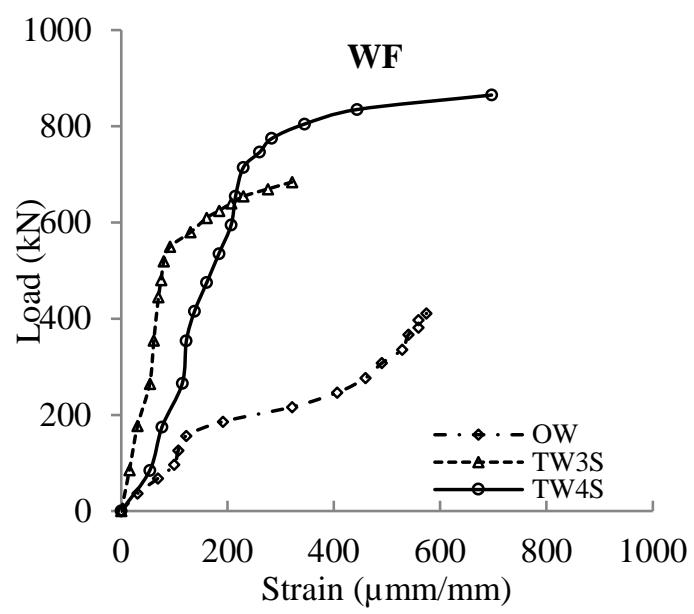

Fig. 20. Load versus strain curves of walls with WF layout 


\section{List of Figures:}

Fig. 1. Walls with and without side supports

Fig. 2. RC wall panels with/without CFRP layouts and strain gauges (all dimensions are in $\mathrm{mm}$ )

Fig. 3. Test frame arrangement

Fig. 4. Typical dial gauge locations on wall panels on the compression side (all dimensions are in $\mathrm{mm}$ )

Fig. 5. Crack patterns on tension side of walls with OW

Fig. 6. Crack pattern on tension side of walls with TW3S

Fig. 7. Crack patterns on tension side of walls with TW4S

Fig. 8. Load versus out-of-plane and in-plane deflection curves of walls with OW (refer to Fig. 4 for gauge locations)

Fig. 9. Load versus out-of-plane and in-plane deflection curves of walls with (refer to Fig. 4 for gauge locations)

Fig. 10. Load versus out-of-plane and in-plane deflection curves of walls with TW4S (refer to Fig. 4 for gauge locations)

Fig. 11. Location of strain gauges on top of CFRP and concrete (interface) of wall OW-CF

Fig. 12. Load versus strain curves of wall OW-CF

Fig. 13. Location of strain gauges on top of CFRP and concrete (interface) for wall TW3S-CF

Fig. 14. Load versus strain curves of wall TW3S-CF

Fig. 15. Location of strain gauges on top of CFRP and concrete (interface) for wall TW4S-CF

Fig. 16. Load versus strain curves of wall TW4S-CF 
Fig. 17. Location of strain gauge on top of CFRP for walls with CF layout

Fig. 18. Load versus strain curves of walls with CF layout

Fig. 19. Location of strain gauge on CFRP for walls with WF layout

Fig. 20. Load versus strain curves of walls with WF layout 